
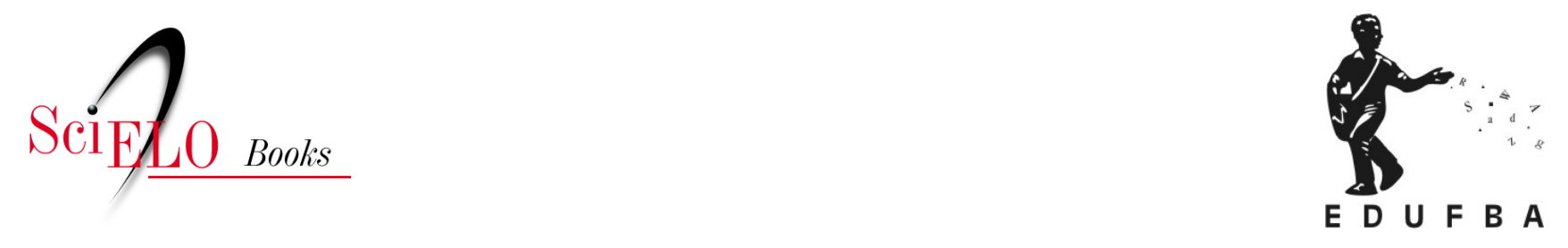

\title{
A agenda habitat das nações unidas sobre as cidades novas incursões na produção dos estudos urbanos
}

\author{
Any Brito Leal Ivo
}

\section{SciELO Books / SciELO Livros / SciELO Libros}

IVO, Any Brito Leal. A agenda habitat das nações unidas sobre as cidades: novas incursões na produção dos estudos urbanos. In: IVO, Anete Brito Leal, ed. A reinvenção do desenvolvimento: agências multilaterais e produção sociológica [online]. Salvador: EDUFBA, 2016, pp. 151-194. ISBN: 978-85-232-1857-7. https://doi.org/10.7476/9788523218577.0005.

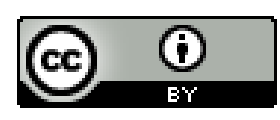

All the contents of this work, except where otherwise noted, is licensed under a Creative Commons Attribution 4.0 International license.

Todo o conteúdo deste trabalho, exceto quando houver ressalva, é publicado sob a licença $\underline{\text { Creative Commons }}$ Atribição 4.0. 


\section{A AGENDA HABITAT DAS NAÇÕES UNIDAS SOBRE AS CIDADES \\ NOVAS INCURSÕES NA PRODUÇÃO DOS ESTUDOS URBANOS}

Any Brito Leal Ivo

As cidades e a questão urbana aparecem, no contexto contemporâneo, como centrais à crise estrutural do capitalismo. (HARVEY, 2009) Como lócus econômico e político, as cidades constituem espaços estratégicos para as dinâmicas econômicas globalizadas e recolocam, atualmente, novos problemas às agendas urbanas, tanto do ponto de vista de infraestrutura e da cidade construída como dos direitos dos cidadãos à cidade, da perspectiva de acesso aos bens públicos e da regulação dos interesses entre agentes externos corporativos e a agenda local. Enquanto o protagonismo das cidades, desde o século XIX, esteve associado à implementação do sistema produtivo relacionado aos processos de industrialização e urbanização, as transformações resultantes dos novos regimes produtivos determinam novos desafios às cidades como espaços de convivência, moradia, reprodução da vida e trabalho, mas também de lazer e de investimentos. O processo de "desterritorialização" das formas produtivas, no regime pós-fordista, deter- 
mina novos arranjos espaciais, derivados de uma estrutura horizontalizada entre agentes em rede, mas esse processo, paradoxalmente, é marcado, ao mesmo tempo, pela centralização do poder econômico. (VELTZ, 1999)

Acompanhando essas mudanças, as cidades e seus governos alteraram a natureza do desenvolvimento urbano, orientado e adaptado agora aos princípios estratégicos de competitividade e eficiência para o mercado. Esses novos arranjos na produção das cidades alteram as relações sociais, espaciais e de poder entre agentes públicos e privados.

$\mathrm{Na}$ verdade, é o conjunto da cidade e do poder que está sendo redefinido. O conceito de cidade, e com ele os conceitos de poder público e de governo da cidade, são investidos de novos significados, numa operação que tem como um dos esteios a transformação da cidade em sujeito/ator econômico [...] e, mais especificamente, num sujeito/ator cuja natureza mercantil e empresarial instaura o poder de uma nova lógica, com a qual se pretende legitimar a apropriação direta dos instrumentos de poder público por grupos empresariais privados. (VAINER, 2007, p. 89)

Inseridas nos "fluxos" globalizados, as cidades reestruturam-se funcional e fisicamente, adaptando-se à dinâmica dos mercados globais, transformando-se, inclusive, em produtos de mercado. Entre os fluxos financeiros mundiais e as disputas pelo capital fluido, as cidades aparecem como o lugar da sobrevalorização do capital corporativo transnacional e,ao mesmo tempo, de "desvalorização" dos atores econômicos locais. Essa subordinação dos atores locais não significa sua passagem a agentes passivos e destituídos de interesses e estratégias. Ao contrário, sua subordinação aos fluxos globais opera com base em arranjos entre grandes corporações internacionais e atores locais fortes (mas também frágeis, por sua condição de subalternidade), em processos de adaptação e captura de oportunidades dos mercados local, nacional e internacional. 
As cidades, como produtos de mercado, disputam, de forma isolada e "desconectada" de suas regiões, os grandes investimentos do mercado e a massa de "consumidores" dispersa mundialmente, como também os ganhos derivados de incentivos dos governos, firmados entre os agentes locais, nacionais e globais. Paradoxalmente à grande "liberdade" dos fluxos financeiros, os investimentos se concentram nas grandes metrópoles, transformando as cidades em lócus de concentração da economia mundial "as cidades estão hoje no coração da economia mundial". (BIDOU-ZACHARIASEN, 2006, p. 21)

Concomitantemente a esses processos de integração das cidades na ordem mundial, os cidadãos lutam por acesso a direitos, inclusive o de participar do destino das cidades. O "direito à cidade", postulado por Lefebvre (2001) ao final dos anos 1960, reatualiza os debates contemporâneos acerca da produção da cidade, colocando em cena não apenas o direito ao uso da cidade e à sua infraestrutura, mas também o debate acerca dos processos decisórios. Nesse contexto, o direito de participar politicamente dos destinos da cidade apresenta-se como questão fundamental. Essa perspectiva é atualizada por Harvey, em Cidades Rebeldes (2014), expoente de novas formas de exercício e de meios reivindicatórios do direito à cidade, em diálogo com a produção lefebvriana.

No contexto assimétrico entre alta competitividade e disputa dos mercados no âmbito mundial e as demandas crescentes de democratização das instâncias decisórias nas cidades, o planejamento urbano estratégico institui-se como um instrumento mediador de ajustamento entre os interesses dos atores internacionais e os agentes locais. Por essa via, reafirma-se um protagonismo das cidades, que é vinculado a um novo modelo de desenvolvimento associado ao regime de acumulação globalizado, o que tensiona com as demandas pelo direito de os cidadãos decidirem sobre os destinos da cidade. Novos jogos de forças, novas instâncias de poder e novos agentes aparecem, subordinando - ou ao menos adaptando - a cidade, seus cidadãos e os investidores partícipes ao mundo globalizado. 
A relação entre o local e o global assume novas dinâmicas e significados no âmbito econômico, fazendo emergir plasticidades na vivência da cidadania e dos citadinos, na nova relação entre a cidade e o capital globalizado, transformando-os em materializações da economia desnacionalizada e liberta em fluxos de capitais. ${ }^{1}$

No lugar do planejamento urbano tradicional, ${ }^{2}$ a urbe é repensada de forma estratégica segundo projetos e programas pactuados com grandes agentes econômicos, numa coletânea de iniciativas pontuais e convergentes com os interesses do capital, aparecendo como um conjunto de atividades segmentadas. $O$ discurso assume o papel de construção simbólica de unidade. (BORJA; CASTELLS, 1998) A malha urbana fragmentada exacerba territorialmente as diferenças, e a cidade dual $^{3}$ se explicita na conformação qualitativa de seus espaços urbanos. Nessa transição, os conceitos de cidade, governo e de res pública são ressignificados, expressando as contradições entre o local e o global, entre a cidadania e o mercado.

Desde 1989, os países e as cidades sofrem os efeitos do que se convencionou chamar de Consenso de Washington. Dez regras básicas são adotadas pelos órgãos financiadores internacionais (FMI, Banco Mundial e Departamento do Tesouro dos Estados Unido) como medidas orientadoras de suas políticas de crédito aplicadas aos países e às cidades, cuja implementação aprofunda a crise das cidades. A imposição dessas medidas, especialmente as de caráter monetarista, envolveu transformações significativas no desenho dos Estados e das municipalidades, orientadas para disciplina fiscal, redução dos gastos públicos, reforma tributária, juros de mercado, abertura comercial, investimento estrangeiro direto, eliminação de restrições, privatização das estatais, desregulamentação (ou afrouxamento) das leis econômicas e trabalhistas e direito à propriedade intelectual. A liberalização dos fluxos de capitais, os ajustes e as reformas dos Estados nacionais afetam a agenda urbana: de um lado, os municípios ganham maior autonomia e passam a se responsabilizar pela execução das políticas sociais; de outro, perdem autoridade devido à presença de novos ato- 
res econômicos externos, da incapacidade financeira e do aumento da crise social, como analisa Anete Ivo (1998, 2001, 2004).

A Constituição Federal brasileira, promulgada ao final dos anos 1980, recoloca em cena as questões políticas relativas à gestão das cidades e aos direitos da cidadania, apontando para a descentralização das políticas sociais, a participação e o controle social das políticas públicas. No entanto, submetidas a constrangimentos do financiamento público, as municipalidades passam a utilizar as parcerias público-privadas como alternativa do financiamento e para o encaminhamento de atividades do planejamento estratégico. Esses ajustes de responsabilidades trazem tensões entre as expectativas democráticas, a agenda do ajuste e os interesses estratégicos das grandes corporações econômicas mediados por um urbanismo coorporativo ${ }^{4}$ como modus operandi da produção de cidades.

Traduzindo esse processo de reestruturação econômica e mudanças políticas no âmbito dos países, as agências multilaterais, especialmente o programa da ONU-Habitat e as ações de apoio e subvenção do Banco Mundial, no Brasil, atuam sobre as cidades contribuindo, entre outras questões, para a reorientação dessa agenda e a reconfiguração das questões urbanas. Este capítulo visa a explorar, de forma introdutória, a influência dessas organizações internacionais na construção das agendas urbanas, observando seus efeitos sobre a produção das ciências sociais, especialmente da sociologia urbana e áreas afins.

Para tanto, a pesquisa toma como ponto de partida as recomendações da Organização das Nações Unidas (ONU) relativas a seu Programa Habitat, bem como os novos objetivos do desenvolvimento sustentável firmados em 2015, entendidos como quadros de pactuação dos Estados com uma agenda comum de desenvolvimento sustentável para as cidades. O texto apresenta, em seguida, um mapeamento dos projetos em curso financiados pelo Banco Mundial, analisando as formas concretas de sua atuação na área urbana, entendendo que o financiamento é uma base estratégica fundamental de intervenção sobre as políticas públicas nas cidades. Por fim, observa-se a relação desses temas com o repertório temático de artigos publicados em pe- 
riódicos que integram a Scientific Electronic Library Online (SciELO), especialmente na área da Sociologia urbana, com base na seleção de palavras-chave destacadas dos documentos das agências.

A análise considerou o desenho institucional da ONU de forma a localizar os quesitos urbanos prioritários nessa área. Acessar esse sistema consistiu em entrar numa estrutura labiríntica de conceitos, definições e diretrizes que evidenciam a complexidade das temáticas, permitindo racionalizações diversas quanto à natureza das questões urbanas tratadas, a reconfiguração das prioridades e os modos atuais de intervenção na agenda urbana, muitas vezes ressignificando-a.

Seguindo essa orientação, neste capítulo, a análise se baseia no programa ONU-Habitat - Programa das Nações Unidas para os Assentamentos Humanos -, criado em 1978, a partir da Conferência das Nações Unidas para Assentamentos Humanos, que ocorreu em Vancouver (Habitat I), elegendo como documentos-base as Declarações elaboradas no Habitat I e II (1976 e 1996) e a Declaração sobre Cidades e Outros Assentamentos para o Novo Milênio. A tradução desses documentos pelo Instituto Brasileiro de Administração Municipal (IBAM) para a Caixa Economica Federal, em 2003, e apresentados pela ONU- Habitat Brasil, tornou-se um documento de referência e interesse dos municípios brasileiros, consistindo em uma orientação para a implementação da Agenda Habitat no Brasil.

A abrangência desses programas e o detalhamento das informações da agenda urbana expõem o potencial de influência e a capilaridade política institucional, demonstrando a complexidade analítica que esse trabalho enfrenta, os desafios que se abrem e também seus alcances e limitações. Ao mesmo tempo, fortalece a pertinência dos objetivos exploratórios deste trabalho, mesmo reconhecendo seu caráter preliminar e as limitações desse arranjo analítico.

Este capítulo dialoga com os objetivos gerais e indicativos metodológicos do projeto $A$ reinvenção do desenvolvimento: agências multilaterais e produção sociológica contemporânea (2012), ${ }^{5}$ relativos à agenda urbana dessas agências, especificamente o Programa ONU-Habitat para os assentamentos humanos. Metodologicamente, a análise do- 
cumental observa duas dimensões de pesquisa sobre as agências. A primeira sistematiza as diretrizes e ações consolidadas pela ONU com base nos objetivos e compromissos do ONU-Habitat, seguindo-se dos compromissos recentemente assumidos pelo Programa das Nações Unidas para o Desenvolvimento (PNUD) na consolidação dos Objetivos do Desenvolvimento Sustentável (ODS), em 2015, no item relativo ao Objetivo 11, sobre as cidades. Essa análise trata, portanto, de um exercício prospectivo de intenções e compromissos firmados pelas Nações Unidas em relação às cidades, em dois períodos e instâncias institucionais: o da Habitat e o da Agenda de 2015 dos ODS.

A segunda dimensão da análise se refere às formas concretas de intervenção do Banco Mundial no financiamento de programas e projetos nas cidades como expressão do fomento do Banco às políticas urbanas orientadas por essa agência. Nesse caso, a ação do Banco traduz-se em práxis do Estado, que encontra, no financiamento do Banco Mundial, uma alternativa orçamentária para a realização de obras e intervenções nas cidades. Na medida em que o Banco financia parte da ação dos governos municipais, estaduais e federais, configura-se sua clara influência nos processos reais de produção das cidades, que serão indiretamente objeto de trabalhos acadêmicos na medida em que avaliam as políticas públicas, os projetos e ações governamentais em curso nas cidades.

A terceira parte deste capítulo analisa a produção de artigos em periódicos da SciELO, especialmente na área da sociologia urbana. Para esse levantamento, foram selecionadas palavras-chave destacadas com base nos documentos da ONU-Habitat - tais como: habitação, moradia, assentamentos, Agenda 21, ${ }^{6}$ desenvolvimento urbano, sustentabilidade, resiliência, pobreza, infraestrutura urbana, questão urbana, violência urbana, governança -, as quais, associadas à palavra "cidade", totalizaram 387 artigos levantados. A seleção das palavras-chave acarreta desafios extras à sistematização dos dados, pelas múltiplas associações disciplinares estabelecidas na agenda urbana da ONU-Habitat. O levantamento com base em uma única palavra-chave não seria fiel à mudança de perspectivas e terminologias ado- 
tadas pelas normativas das agências multilaterais. Ou seja, em função da complexidade e das mudanças nos prognósticos urbanos formulados pelas agências multilaterais, buscou-se, dentro do possível, levantar os termos encontrados nos documentos da ONU-Habitat, de forma a estabelecer operativamente maior relação de significância entre os dispositivos das agências e o campo de produção das ciências sociais, de uma perspectiva ainda exploratória.

Considerando esses objetivos e estratégias analíticas, o texto se estrutura em três níveis de análise.

O primeiro baseia-se nas diretrizes de ação e nos compromissos formulados pelas Nações Unidas na pactuação de diretrizes norteadoras para a agenda urbana, com base no Programa ONU-Habitat. A Declaração de Vancouver sobre Assentamentos Humanos, a Declaração de Istambul sobre Assentamentos Humanos e a Declaração sobre Cidades e Outros Assentamentos Humanos no Novo Milênio são os documentos-chave de análise para a agenda urbana focalizada neste capítulo, com suas mudanças e paradigmas.

Um segundo nível de análise identifica as ações de financiamento do Banco Mundial a projetos urbanos no Brasil, a partir do ano 2000. O mapeamento desses programas em andamento no território brasileiro, apoiados pelo Banco Mundial, expressa a natureza das atividades de intervenção e de apoio a projetos concretos. A identificação e o mapeamento desses projetos nas cidades traduzem as orientações assumidas pelo Banco para o desenvolvimento urbano.

No terceiro nível de análise, busca-se levantar a produção acadêmica das ciências sociais com base em palavras-chave destacadas pelas agências e relativas à agenda urbana, especialmente na área da sociologia, conforme definição já mencionada. Esse levantamento tem caráter preliminar e busca, sobretudo, apontar tendências e possíveis nexos entre a produção nacional dos estudos urbanos na área da sociologia e as diretrizes da ONU-Habitat, ou em relação às formas concretas da ação do Banco Mundial no apoio ao financiamento de projetos no Brasil. 
Esses três níveis de análise permitirão formular algumas hipóteses exploratórias sobre as mútuas influências entre as normativas das agências, seus campos temáticos, abarcados pela produção do conhecimento dos periódicos da coleção SciELO, e as problemáticas postuladas pelas agências multilaterais para as cidades, nesse caso pela ONU-Habitat e pelos projetos financiados pelo Banco Mundial no Brasil.

\section{A ONU-HABITAT - Programa das Nações Unidas para os Assentamentos Humanos}

O Programa das Nações Unidas para os Assentamentos Humanos (ONU-Habitat) foi criado em 1978, como resultado da Conferência das Nações Unidas sobre Assentamentos Humanos (Habitat I) e tem por responsabilidade coordenar ações sobre Assentamentos Humanos mediante a troca global de informações sobre moradia e desenvolvimento sustentável, oferecendo assessoramento técnico frente aos "os crescentes desafios enfrentados por cidades de todos os tamanhos". (ONU-Habitat, 2016) Ele compreende 154 programas técnicos, em andamento em 61 países.

As atividades operacionais da agência ajudam governos a criar políticas e estratégias que visam ao fortalecimento de uma gestão autossuficiente no âmbito nacional e local. Concentram-se na promoção de moradia para todos, no melhoramento da governança urbana, na redução da pobreza nas cidades e na meIhoria do entorno nos lugares onde moram os mais pobres. (ONU-Habitat, 2016)

Os objetivos do ONU-Habitat estão em consonância com os objetivos globais da ONU, com especial atenção à Declaração do Milênio (2000), com os compromissos dos países a serem cumpridos até 2015. Apesar de esse documento não tratar diretamente das questões urbanas, destacam-se, nele, o fortalecimento do estado democrático de direito como basepara a efetivação dos Direitos Humanos ${ }^{7}$ e o com- 
promisso de erradicar a pobreza e as suas condições desumanas, elementos fundamentais aos direitos dos cidadãos nas cidades.

Como esforço de garantir o acesso à moradia adequada e aos serviços básicos e seguros, além do melhoramento dos assentamentos precários até 2030, o novo Objetivo 11 dos Objetivos Globais da ONU trata das cidades e dos assentamentos sustentáveis: "Tornar as cidades e os assentamentos humanos inclusivos, seguros, resilientes ${ }^{8}$ e sustentáveis". (ONU Brasil, 2016) Como questões fundamentais para a melhoria da qualidade de vida nas cidades até o ano de 2030 , são enunciadas as áreas de ação: habitação, transporte, urbanização, gestão e planejamento urbano, patrimônio cultural e natural, catástrofes, espaços públicos, relação econômica entre o urbano, o periurbano e áreas rurais. Essas pautas são acompanhadas por recomendações relativas a processos democráticos, a exemplo das recomendações sobre acesso, inserção, inclusão e participação social. A ênfase nas ações de prevenção de riscos e catástrofes associa-se à noção de resiliência a desastres, conforme é descrito no Objetivo 11 da Plataforma dos ODS (Tornar as cidades e os assentamentos humanos inclusivos, seguros, resilientes e sustentáveis).

Até 2020, aumentar substancialmente o número de cidades e assentamentos humanos, adotando e implementando políticas e planos integrados para a inclusão, aeficiência dos recursos, mitigação e adaptação às mudanças climáticas, a resiliência a desastres; e desenvolver e implementar, de acordo com o Marco de Sendai para a Redução do Risco de Desastres 20152030, o gerenciamento holístico do risco de desastres em todos os níveis. (ONU-Brasil, 2016)

Seguindo a prioridade atual - prevenção de riscos e desastres -, o marco para a Redução de Riscos e Desastres 2015-2030 enfatiza a necessidade de criação de políticas públicas mais eficientes na gestão de desastres, na prevenção de catástrofes e na redução de áreas vulneráveis. Questões essencialmente referentes à agenda urbana e outras da agenda social são apresentadas como elementos-chave no 
combate aos desastres e na redução de riscos nas cidades, tais como pobreza e desigualdade social, urbanização rápida e não planejada, má gestão do solo, mudanças demográficas, limitada disponibilidade de tecnologia, usos insustentáveis de recursos naturais, ecossistemas em declínio, pandemias e epidemias. Os modelos gestores e os processos de governança são apontados como ações necessárias à redução dos riscos a desastres.

Esses desdobramentos da ação preventiva a desastres e riscos ilustram a complexidade das agendas urbanas apresentadas pela ONU e pela ONU-Habitat. Esse marco dará origem, no Brasil, à campanha Construindo Cidades Resilientes (2012) que, na forma de um guia, apresenta os princípios e a importância da construção de cidades seguras e resilientes. (UNISDR, 2012) Em 2015, o Brasil sediou a Reunião de Trabalho Construindo Cidades Resilientes a partir do novo Marco de Sendai (Campinas, SP) e a Oficina de Capacitação Resiliência e Redução do Risco no Ambiente Urbano: Desenvolvimento de Capacidades para a Construção de Cidades Resilientes (Curitiba, PR). O governo brasileiro, juntamente com aUnited Nations Office for Disaster and Risck Reduction (UNISDR) criou o Centro de Excelência para a Redução do Risco de Desastres (UNISDR-CERRD) com o objetivo de incluir a prevenção de catástrofes como componente central para um desenvolvimento sustentável, promovendo a articulação de diversos centros de pesquisa nacionais. No entanto, após dois anos de funcionamento, e sob a perspectiva de fechamento do Centro de Excelência, os 26 centros de pesquisa associados a essa ação no Brasil assinaram uma Carta Aberta, em que solicitam o seu não fechamento, uma vez que essa medida "sinaliza ao mundo que estamos abnegadamente abandonando a política de colocar nosso país como um ator global capaz de estabelecer diálogos qualificados nesse tema de tanta relevância na atualidade". (CARTA ABERTA, 2015)

Esse segmento da agenda "urbana", em termos de prevenção dos riscos ambientais, evidencia formas de articulação entre as agências multilaterais e os poderes locais e ilustra como essas agências se associam com a comunidade acadêmica nacional, apresentando no- 
vos alvos de atenção, novos sentidos e significados para as questões urbanas, ao tempo em que constroem afinidades e prioridades na atenção pública. Na medida em que novas temáticas são problematizadas, sugerem-se pautas comuns de soluções para os problemas formulados e orientam-se novas teses. Esses diagnósticos prospectivos resultam em formas práticas de redesenho da agenda sobre a cidade. Os documentos balizadores da atuação da ONU-Habitat apresentam, assim, deslocamento da agenda urbana no tempo, influenciando a produção acadêmica das ciências sociais brasileiras sobre o urbano, na forma de pactuação e implementação da agenda. No entanto, essa agenda é também influenciada pela produção técnica e acadêmica preexistente e pelos problemas efetivos a serem enfrentados, promovendo-se um contínuo movimento de retroalimentação entre os atores, os governos, as agências, as formas efetivas de intervenção no espaço construído e a pesquisa acadêmica.

As conferências do UN-Habitat - Vancouver (1976) e Istambul (1996) e os Fóruns Urbanos Mundiais - formam um panorama onde a análise da urbanização pode ser localizada e, independentemente da eficácia das respostas dos programas propostos, abrem indagações sobre o enfoque dos velhos problemas da urbanização e dos limites da mediação institucional sobre os processos econômicos e sociais. (ANRONUCCI et al.., 2009)

\section{A Declaração de Vancouver sobre Assentamentos Humanos (1976)}

A Declaração de Vancouver sobre Assentamentos Humanos e o Plano de Ações de Vancouver constituem as primeiras diretrizes específicas no tratamento das questões urbanas formuladas pelas ONU-Habitat. Frente ao reconhecido crescimento das cidades e o processo de urbanização em grande escala, somados à ausência e ou à fragilidade dos instrumentos de planejamento, a Conferência das Nações Unidas para Assentamentos Humanos reconhece o processo de urbanização 
crescente como um problema mundial merecedor de cuidados específicos, inaugurando, assim, uma pactuação da agenda urbana formulada pela ONU-Habitat: a Agenda Habitat.

Nesses documentos, o Estado é reconhecido como agente forte e necessário à implementação e formulação de políticas públicas para as cidades, com especial atenção à elaboração e viabilização das políticas de habitação e melhoramento da infraestrutura urbana, consideradas como meios básicos de melhoria da qualidade de vida nos assentamentos precários urbanos, bem como de enfrentamento das desigualdades e amenização das condições de vida precárias dos segmentos em condição de maior vulnerabilidade socioeconômica nas cidades.

O conjunto de princípios estabelecidos pela declaração de Vancouver sobre Assentamentos Humanos apresenta, como valor primordial, a construção de cidades mais equitativas: "Políticas de assentamentos humanos podem ser ferramentas poderosas para uma distribuição mais equitativa e da renda e de oportunidades".$^{10}$ (ONU-Habitat, 1976b, tradução nossa) A cidade torna-se protagonista da Agenda Habitat com objetivos relacionados à natureza equânime do espaço construído e do acesso aos serviços públicos que se localizam nas cidades. O desenvolvimento econômico, segundo esses documentos, deve proporcionar a satisfação das necessidades humanas, consistindo em um meio para se alcançar a melhoria da qualidade de vida dos seus habitantes.

A relação entre o urbano e o rural aparece de forma complementar às questões urbanas formuladas. As intervenções, nas áreas rurais, são apresentadas como necessárias à redução dos fluxos migratórios, prevalecendo, assim, a relevância do urbano sobre o rural, naquele momento. Esses documentos apresentam um rol de questões e seus possíveis encaminhamentos, mas reconhecem como fundamental que os assentamentos degradados e a habitação não podem estar dissociados das questões sociais e econômicas.

Duas recomendações primordiais estruturam as orientações na melhoria das cidades: o acesso à terra, visto como recurso limitado e 
escasso, e a participação ampla dos cidadãos para a pactuação sobre projetos e propostas para as cidades. Na primeira, o Estado tem papel primordial na elaboração de arcabouço legal para a fiscalização e regulamentação de usos e meios de acesso à terra.

A terra é um dos elementos fundamentais nos assentamentos humanos. Todo Estado tem direito de tomar as medidas necessárias para manter sob o controle público o uso, a posse, a alienação e a reserva da terra. Todo Estado tem o direito de planejar e regular o uso da terra, que é um de seus recursos mais importantes, de tal forma que o crescimento dos centros populacionais urbanos e rurais seja baseado em um plano abrangente de utilização. Tais medidas devem assegurar a realização dos objetivos fundamentais da reforma social e econômica para todos os países, em conformidade com o seu sistema nacional fundiário e a legislação. ${ }^{11}$ (ONU-Habitat, 1976a, tradução nossa)

A participação social dos habitantes é considerada elemento fundamental à inserção social. Nesse contexto, a criação de novas habitações e o melhoramento das moradias existentes bem como a melhoria da infraestrutura urbana básica são vetores determinantes da atuação dos governos na reversão do quadro de precariedade das e nas cidades.

A maior prioridade deve ser colocada na habilitação de pessoas expulsas e sem-teto que foram deslocadas por catástrofes naturais ou provocadas pelo homem e, especialmente, pelo ato de agressão estrangeira. Nesse último caso, todos os países têm o dever de cooperar plenamente a fim de garantir que as partes envolvidas permitam o regresso dos deslocados às suas casas e dar-lhes o direito de possuir e desfrutar de suas propriedades e pertences sem interferência. ${ }^{12}$ (ONU-Habitat, 1976a, tradução nossa)

Esses princípios consolidaram-se em ações no Plano de Ação de Vancouver. Com 64 orientações, o Plano se estrutura em cinco dimensões: Políticas e Estratégias de Assentamentos; Planejamento de Assen- 
tamentos; Abrigo, Infraestrutura e Serviços; Terra, Participação Pública e Gestão e Administração. Tais dimensões constituem-se em campos estratégicos de ação para se alcançarem os objetivos e as metas da política de assentamentos propostos no Habitat I. As ações indicadas deverão integrar uma política de desenvolvimento mais ampla para o melhoramento físico desses assentamentos - infraestrutura e habitação - e constituem-se também num campo econômico estratégico para a economia e a criação de empregos.

$\mathrm{Na}$ verdade, a própria construção dos componentes físicos dos assentamentos humanos - sejam eles rurais ou urbanos, sob a forma de habitações ou estradas, com tecnologias tradicionais ou modernas -, em volume suficiente para atender às necessidades da sociedade, poderia se tornar-se um setor líder da economia e um importante gerador de emprego, em vez de ser tratado como residual das chamadas atividades 'produtivas'.13 (ONU-Habitat, 1976b, tradução nossa)

A participação da cidadania aparece como condição prioritária para a mudança das condições de vida nas cidades, devido à magnitude dos problemas aí existentes. Assim, apesar de a Conferência de Vancouver postular o protagonismo do papel do Estado na elaboração de políticas para os assentamentos humanos, ela também reconhece que os agentes públicos não possuem condições de tratar essas questões sem um maior envolvimento de agentes privados e da sociedade civil. Com isso, defende a criação e o fortalecimento das instâncias participativas para elaboração de planos de ação e projetos para os assentamentos humanos, estimulando a sua conscientização e a possibilidade de processos inovadores.

O esforço cooperativo das pessoas e de seus governos é pré-requisito para uma ação efetiva sobre os assentamentos humanos. A magnitude e a intratabilidade dos problemas são grandes demais para os governos agirem sozinhos. A participação dos cidadãos constitui parte integrante dos processos de tomada de decisão 
em toda a gama de questões de assentamentos humanos. Aos cidadãos devem ser fornecidas oportunidades para envolvimento direto nas decisões que afetam profundamente suas vidas. Tal participação pode aumentar a consciência dos cidadãos sobre a complexidade e a inter-relação dos problemas e a necessidade urgente de concertação. $O$ envolvimento dos cidadãos também pode ser um meio importante de fazer uso criativo de sua engenhosidade e habilidades, tornando, assim, eficaz o uso de fontes muitas vezes inexploradas. ${ }^{14}$ (ONU-Habitat, 1976b, tradução nossa)

Esses dois documentos têm relevância para a problematização das questões urbanas prospectadas pelos programas das Nações Unidas. São postas, à mesa de debate, as seguintes questões: o papel do Estado na condução e elaboração de políticas urbanas, o controle sobre o solo urbano como alicerce ao acesso de direitos fundamentais - moradia e os relacionados aos serviços públicos - e, por fim, desenha-se um modelo participativo como instância fundamental para a construção dos encaminhamentos partilhados entre governo e sociedade civil. Mesmo defendendo os processos de participação ou o reconhecimento de iniciativas individuais para solução das questões de moradia e de infraestrutura urbana, na forma de admissão da importância das parcerias entre o público e o privado, esses documentos reconhecem também a relevância do Estado no encaminhamento dessas questões e a implementação desses novos modelos gestores para as cidades.

\section{A Declaração de Istambul sobre Assentamentos Humanos - ONU-Habitat (1996)}

Duas décadas após a publicação da Declaração de Vancouver sobre Assentamentos Humanos, a Agenda Habitat I (1976) e a Agenda Habitat II (Istambul, 1996) renovam as orientações sobre políticas na ONU-Habitat.

Esta conferência em Istambul marca uma nova era de cooperação, uma era da cultura da solidariedade. À 
medida que entramos no século XXI, nós oferecemos uma visão positiva dos assentamentos humanos sustentáveis, um senso de esperança para o nosso futuro comum e um estímulo para enfrentarmos um desafio verdadeiramente válido e comprometedor, o de construirmos juntos um mundo onde todos possam viver em uma morada segura, com a promessa de uma vida decente, com dignidade, boa saúde, segurança, felicidade e esperança. (DECLARAÇÃO DE ISTAMBUL..., 1996)

A "Moradia Adequada para Todos" e o "Desenvolvimento de Assentamentos Humanos Sustentáveis ${ }^{15}$ em Todo o Mundo" são os dois eixos estruturantes desse documento. Com a perspectiva de alcançar um desenvolvimento sustentável, o desenvolvimento social e econômico associado à proteção ambientalconstituemos alicerceres dessas novas orientações firmadasmundialmente. O montante de pessoas que habitam as cidades, as perspectivas de crescimento populacional urbano e a natureza do processo de urbanização representam desafios que colocampara ascidades como lugar central para redução das desigualdades e o desenvolvimento das nações.

Nós avaliamos, em caráter de urgência, a contínua deterioração das condições de habitação e dos assentamentos humanos. Ao mesmo tempo, reconhecemos as cidades grandes e pequenas como centros de civilização, geradoras de desenvolvimento econômico, social, espiritual e de avanços científicos. Devemos aproveitar as oportunidades apresentadas por nossos assentamentos e preservar a sua diversidade para promover a solidariedade entre todos os nossos povos. (DECLARAÇÃO DE ISTAMBUL..., 1996)

Essa perspectiva se desdobra em atendimentos específicos a grupos sociais e demográficos que assumem prioridade da atenção pública, aos quais se associa também a construção de assentamentos humanos sustentáveis. Portanto, esses assentamentos humanos traduzem-se emalvos de superação da pobreza, em atenção a segmentos 
específicos da população, como mulheres, crianças e jovens, idosos e pessoas com deficiência, e também os indígenas e os grupos em situação de vulneralibidade e pobreza.

Na Declaração de Vancouver (1976), o acesso à terra aparecia como instrumento preponderante para o enfrentamento de desigualdades. Nesse documento de Istambul (1996), a atenção se desloca para o acesso à moradia - seja pela criação de novas moradias, ou pela meIhoria das existentes. $\mathrm{O}$ acesso à moradia segura e saudável constitui uma condição fundamental do acesso à cidadania. Outra reorientação, observada no espaço de tempo entre a Declaração de Vancouver (1976) e a Agenda Habitat (1996) diz respeito ao papel do Estado. Enquanto, em 1976, a agenda reconhecia o protagonismo estatal na condução de projetos e ações, a Agenda Habitat (1996) reconhece também o mercado como agente importante desse processo. $\mathrm{O}$ acesso à moradia e a construção de assentamentos humanos aparecem, então, como vetores econômicos do desenvolvimento local. As soluções tecnológicas e a criação de linhas de crédito, assim como a articulação para ampliação de recursos para o setor de moradia, são indicadas como ações alternativas a um contexto marcado por "assentamentos precários".

O princípio da participação se reafirma também como orientação para a consolidação e a construção de pactos entre os agentes públicos e privados da sociedade civil. Nesse caso, a habilitação de atores locais e sua capacitação são pressupostos para a condição igualitária da participação nos processos decisórios. A transparência e a adoção de processos de tomada de decisão "abertos" são consideradas condições sine qua non para o fortalecimento da cidadania nas cidades. Importa pontuar, ainda, o protagonismo das autoridades locais, consideradas grupo de grande relevância na implementação dessa Agenda, na Conferência Habitat II (1996).

Assim, a distribuição geográfica dos assentamentos humanos torna-se elemento de construção de um "ambiente de cidadania". Nesse sentido, a relação entre o rural e o urbano deve ser mais equilibrada, reconhecendo-se a interdependência mútua dessas popula- 
ções e territórios. O rural é apontado como espaço de oportunidade real de desenvolvimento. A gestão e a criação de infraestrutura constituem não só condições para a redução dos fluxos migratórios, mas núcleos difusores de processos de desenvolvimento territorial e local.

\section{A Declaração sobre Cidades e Outros Assentamentos Humanos no Novo Milênio - ONU-Habitat (2001)}

A Declaração sobre Cidades e Outros Assentamentos Humanos no Novo Milênio reafirma e ratifica os compromissos da Agenda Habitat (1996) no que diz respeito à Habitação Adequada para a construção de Assentamentos Humanos Sustentáveis, considerando que $50 \%$ da população mundial residem em cidades e que $1 / 4$ da população urbana vivem abaixo da linha de pobreza. Esses números e o processo de urbanização acelerado colocam as cidades como um lócus problemático, que enfrenta problemas relativos à criação suficiente de empregos, à provisão adequada de moradia e ao atendimento das necessidades básicas dos cidadãos.

Observamos, com grande preocupação, as condições atuais dos assentamentos humanos em todo o mundo, especialmente conforme documentado no terceiro Relatório Global sobre Assentamentos Humanos. A despeito dos esforços dos Governos e seus parceiros da Agenda Habitat para cumprir seus compromissos, a pobreza disseminada continua a ser o principal obstáculo, e as condições ambientais precisam ser significativamente aprimoradas em muitos países. Criticamente, a maioria das pessoas que vive em condição de pobreza ainda não tem garantia jurídica da posse de suas moradias, enquanto outras sequer possuem um teto básico. Assim, ainda perduram sérios empecilhos ao desenvolvimento de Assentamentos Humanos Sustentáveis. (DECLARAÇÃO SOBRE CIDADES..., 2003)

Esse cenário de reconhecida precariedade das condições de vida coloca as cidades como território estratégico para a erradicação da pobreza em todo o mundo. Atribui-se às cidades um papel 
prioritário nos desafios resultantes do crescimento da pobreza - expressos em termos de falta de moradia, desemprego, ausência de serviços básicos, expulsão de grupos marginalizados e fragmentação -, reconhecendo-se a relevância econômica dos municípios e cidades, assim como das parcerias público-privadas nesse encaminhamento: as cidades são apresentadas, então, como instâncias que permitem "maximizar os benefícios" e compensar, ao mesmo tempo, as "consequências da globalização".

Além da identificação dos obstáculos e desafios para a implementação da Agenda Habitat (1996), aparece um novo elemento, que estabelece um nexo entre participação e prevenção da corrupção, na promoção dos objetivos públicos. Nesse sentido, o fortalecimento das instituições e das estruturas jurídicas recebe atenção na regulação dessas relações políticas e sociais. Também os problemas identificados da criminalidade e as violências urbanas, assim como o terrorismo e as questões da guerra, passam também a integrar o diagnóstico dos problemas urbanos contemporâneos.

A pobreza urbana aparece como o maior problema a ser enfrentado na implementação da Agenda Habitat, que a ela acrescenta o acesso à água para todos e à infraestrutura para tratamento sanitário e de resíduos sólidos como objetivos prioritários, considerando os compromissos com a gestão adequada dos recursos ambientais.

\section{A reprodução da agenda Habitat no Brasil: Agenda Habitat para Municípios - ONU-Habitat Brasil (2003)}

A "Agenda Habitat para Municípios" constitui um documento-síntese da Agenda Habitat (aprovado no Habitat II-1996, elaborado dois anos antes dessa Conferência), acrescido de orientações para sua implementação no Brasil, e traz comentários e análises específicas à realidade brasileira e às questões dos assentamentos humanos no país. Diversamente dos documentos mais globais, ele apresenta, na sua introdução, dados mais específicos para o Brasil, referentes a desigualdades na distribuição de renda e no acesso a moradias: 
A desigualdade da distribuição de renda é dramática: 1,0\% da população detêm a mesma quantidade de recursos que os $50 \%$ mais pobres; e os $20 \%$ mais ricos possuem renda 33 vezes maior que os $20 \%$ mais pobres. Com base no Censo de 2000, o déficit habitacional estimado é de 6,7 milhões de domicílios, sendo 5,4 milhões na área urbana, sendo que $91,6 \%$ desse déficit urbano é composto por famílias com renda de até cinco salários mínimos. (AGENDA HABITAT..., 2003)

Frente a essa estrutura histórica desigual é que as orientações e princípios da ONU-Habitat são interpretados, ratificados e referendados:

Tenho esperança de que este documento será usado no Brasil, assim como nos países de língua portuguesa, para o fortalecimento das políticas e da gestão dos assentamentos humanos, com o objetivo de promover o seu desenvolvimento sustentável. O UN-HABITAT, por meio de seus escritórios regionais e de seus programas especializados, está pronto para colaborar com parceiros nacionais e locais para que os Municípios brasileiros possam implementar integralmente os compromissos e as estratégias da Agenda Habitat. (AGENDA HABITAT..., 2003)

Importa, ainda, indicar o papel protagonista dos poderes locais na implementação dessa agenda, destacadocomo positivo e favorável no texto brasileiro. A Agenda Habitat para os Municípios apresenta um resumo dos textos e mantém a estrutura original dos três capítulos. O preâmbulo reconhece a precariedade crescente das condições de vida de grande parte da população mundial e indicaa necessidade de intervençãonas cidades como fator determinante para a reversão desse quadro. Esse capítulo aponta a interação entre os agentes públicos e privados na condução dosprocessos transformadores, que afirmem uma visão positiva dos assentamentos humanos, reforçando o compromisso da ONU- Habitat de conseguir abrigo digno e seguro para todos - em especial para aqueles que se encontram em estado de vulnerabilidade e pobreza -, uma ação necessária ao desenvolvimento sustentável. 
Quanto mais cedo as comunidades, os Governos locais e as parcerias - entre os setores público, privado e comunitário - juntarem esforços para criar estratégias abrangentes, corajosas e inovadoras para habitação e assentamentos humanos, melhores serão as perspectivas para segurança, saúde e bem-estar dos povos e melhor será o panorama para soluções para o meio ambiente global e os problemas sociais. (AGENDA HABITAT..., 2003)

Não obstante o protagonismo das grandes cidades - quer pelas oportunidades de emprego e condições de vida, quer pela magnitude dos problemas urbanos como pobreza e precariedade da vida humana -, a Agenda Habitat Brasil traz também uma especial atenção ao rural e às pequenas cidades, como possibilidades reais para a redução das desigualdades mediante investimentos tecnológicos para o desenvolvimento. Segundo esse documento, a interação entre cidades e a relação entre o urbano e o rural se fazem mediante o fluxo de mercadorias, recursos e pessoas.

Seguindo a estrutura apresentada, no segundo capítulo, os compromissos e metas da Agenda Habitat consideram dois objetivos: o da moradia para todos e o do desenvolvimento. No que diz respeito aos assentamentos precários, o documento reconhece expressamente a urbanização de favelas como forma pragmática para a solução do déficit habitacional urbano.

Cabe aos Estados a implementação dessas agendas, com destaque especial para a erradicação da pobreza - alicerce para o desenvolvimento sustentável. $\mathrm{O}$ atendimento das necessidades básicas, dentre elas as que são relacionadas à qualidade do espaço construído, é apresentado como pressuposto para a qualidade de vida e a construção de "Assentamentos Humanos Equitativos".

Assentamentos Humanos Equitativos são aqueles em que todas as pessoas, sem discriminação de qualquer tipo quanto à raça, cor, sexo, religião, opinião política ou outra, origem nacional ou social, propriedade, nascimento, ou outro status, têm igual acesso à moradia, 
infraestrutura, serviços de saúde, água e alimentação adequadas, educação e espaços abertos. Além disso, tais assentamentos humanos proporcionam oportunidades iguais para uma vida produtiva e escolhida livremente, igual acesso a recursos econômicos, incluindo o direito à herança, à posse da terra e outras oportunidades de crédito e recursos naturais e tecnologia apropriadas; oportunidades iguais para o desenvolvimento pessoal, espiritual, religioso, cultural e social; oportunidades iguais para a participação em processos decisórios, direitos e obrigações no que diz respeito à conservação e ao uso de recursos naturais e culturais; igual acesso a mecanismos de garantia de que direitos não são violados. O maior poder às mulheres e sua total participação em bases de igualdade em todas as esferas da sociedade - seja rural ou urbana - são fundamentais para o desenvolvimento de assentamentos de humanos sustentáveis. (AGENDA HABITAT..., 2003)

Por fim, apresentam-se os compromissos e metas, considerando-seque a qualidade de vida nas cidades deriva não apenas das condições qualitativas do meio ambiente construído, mas também do acesso a serviços públicos, como saúde e educação, assim como do acesso ao mundo do trabalho, sintetizando, no urbano, os problemas históricos relacionados à reprodução da vida e trabalho das camadas populares nas cidades, no contexto do desenvolvimento capitalista.

\section{Projetos financiados pelo Banco Mundial em andamento no Brasil}

O mapeamento de projetos apoiados pelo Banco Mundial no Brasil evidencia, no âmbito da ação efetiva, como o Banco influencia a política urbana nacional e, num outro sentido, permite inferir a confluência ou não entre os discursos e compromissos formuladas pela agenda ONU-Habitat com o financiamento do Banco Mundial, em ações concretas. Ao mesmo tempo, os projetos e ações em processo de implementação no Brasil, hoje, também ilustram estratégias de governo 
e eventuais distorções entre os princípios da agenda e as atividades e prioridades assumidas na prática pelo financiamento dos projetos.

O Banco Mundial compartilha as orientações da Agenda 21 (Rio 92), apresentando a meta de reduzir a pobreza à metade até 2030.

O grupo do Banco Mundial tem entrado em uma nova era ao adotar objetivos mensuráveis para pôr fim à pobreza extrema em todo o mundo até 2030 e promover a prosperidade compartida, metas que procurará alcançar de um modo sustentável no ambiental, social e económico. Para atingir esses objetivos, será necessário reconhecer que o crescimento por si só não conduzirá ao bem-estar sustentável e inclusivo. O aumento dos níveis de mal-estar social em todo o mundo foi provocado, em parte, por uma maior desigualdade económica e pela falta de oportunidade de incluso. Atingir esses objetivos supõe uma maior cooperação entre os associados na tarefa do desenvolvimento, entre os que figuram as organizações multilaterais e os Estados que as compõe. Esta cooperação é essencial em um momento de contínua incerteza económica em todo o mundo. ${ }^{16}$ (WORLD BANK, 2013, p. 7, tradução nossa)

Em seu Relatório Anual Geral de 2013, o Banco Mundial apresenta a distribuição do financiamento por setor, dos anos 2008 a 2013. Não obstante seu comprometimento com a agenda de erradicação da pobreza, os maiores recursos foram destinados ao setor financeiro e ao setor privado, representando $21 \%$ dos empréstimos efetivados (Gráficos 1 e 2). Os valores destinados ao desenvolvimento humano e social representam, juntos, aproximadamente 15\% dos recursos financiados pelo Banco Mundial nesse período. Menos de 1\% é destinado ao desenvolvimento urbano, e o desenvolvimento rural recebeu mais ou menos $11 \%$ do financiamento. Os dados mostram que o financiamento dos projetos privilegia o setor financeiro e privado - o que não necessariamente garante o alcance da meta de redução à metade da pobreza mundial. 
Gráfico 1 - Financiamento geral do Banco, por setor de atividade, 2008-2013

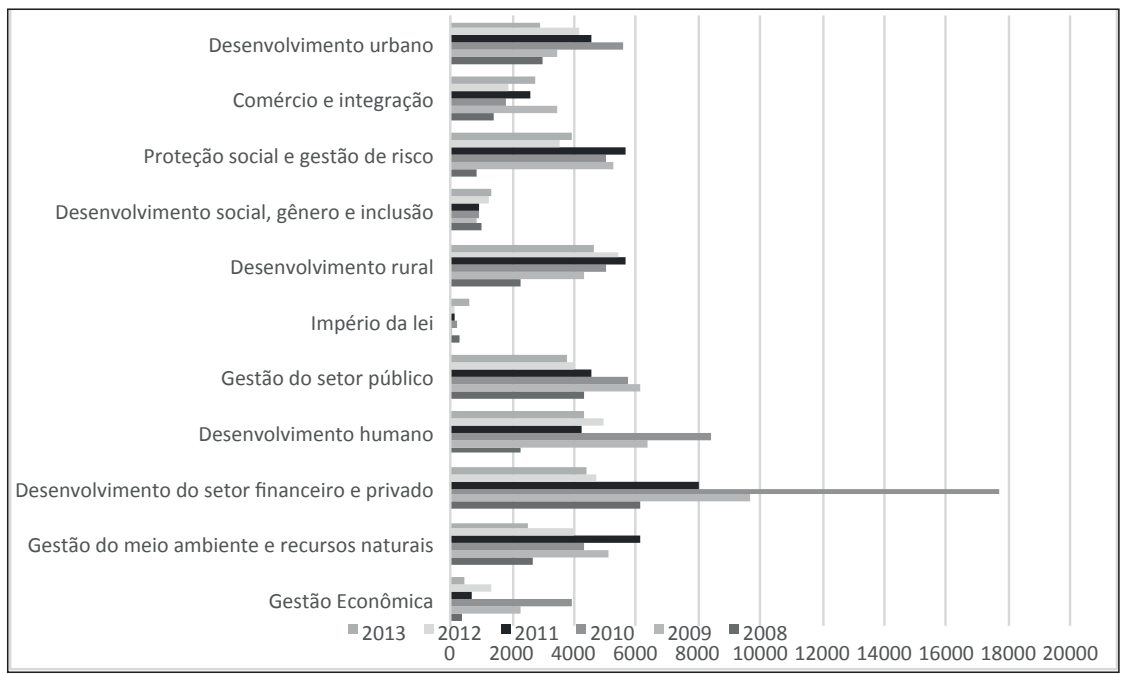

Fonte: elaboração do autor com base em World Bank (2013).

Gráfico 2 - Financiamento do Banco Mundial no mundo, por temas2008-2013

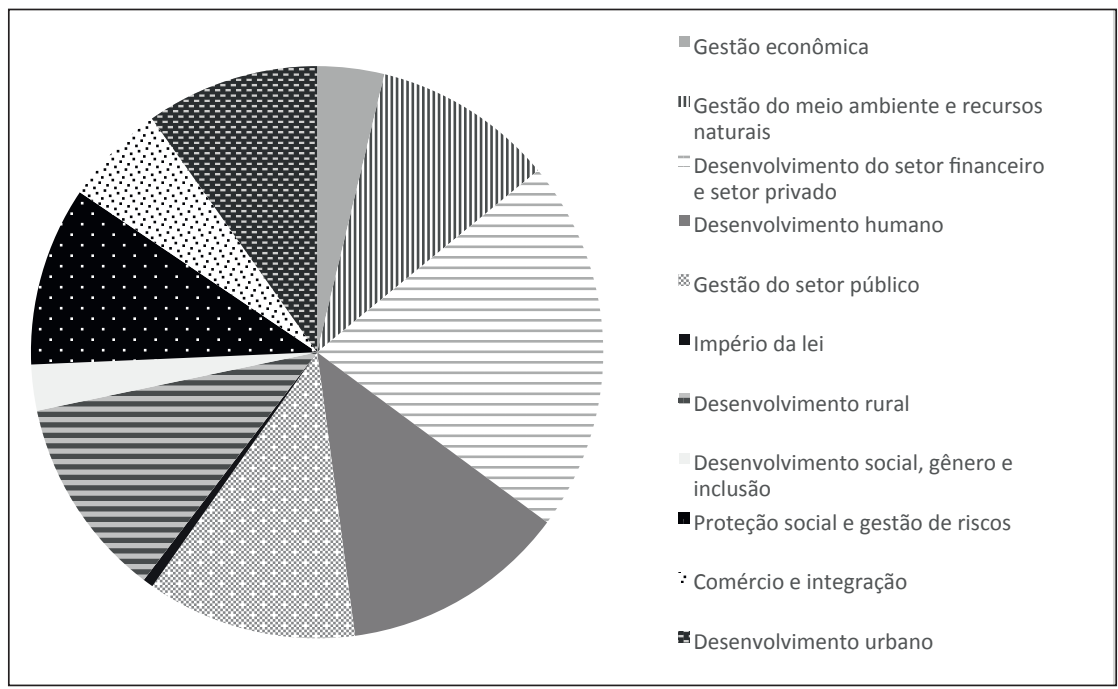

Fonte: elaboração do autor com base em World Bank (2013). 
Figura 1 - Mapa de projetos financiados pelo Banco Mundial, no Brasil

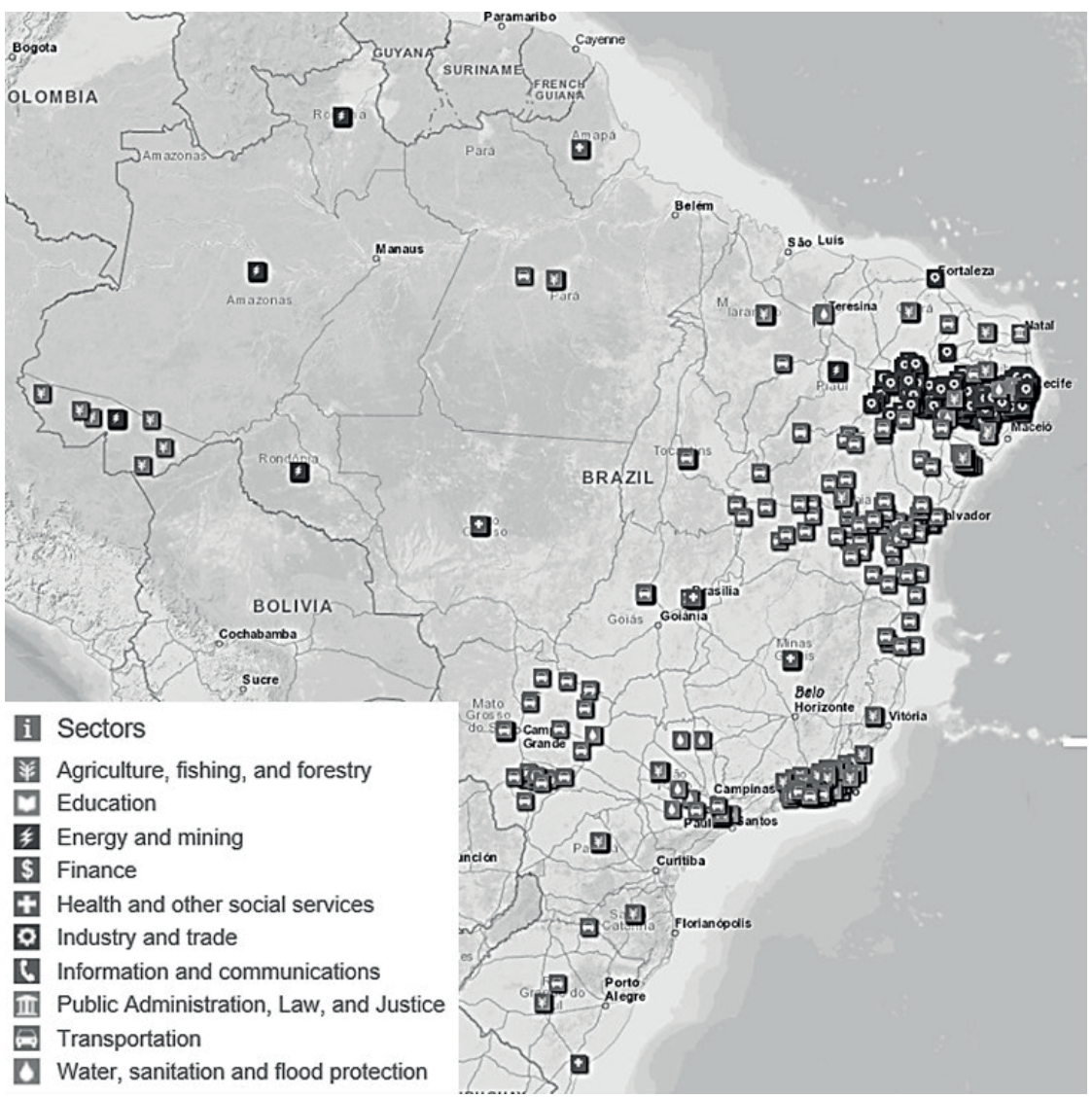

Fonte: World Bank (2016).

O Mapa dos projetos (Figura 1) informa que, atualmente, são 42 projetos desenvolvidos com apoio do Banco Mundial no Brasil, mobilizando $\$ 6,99$ bilhões de dólares, em 553 localidades diferentes. O levantamento desses projetos no mapa contabiliza 22 projetosem 345 localidades, envolvendo as cinco regiões nacionais, comum total aproximado de $4 \$$ bilhões de dolares de investimento (Gráfico 3). São dez imagens (que representam tipos de intervenções) que classificam os projetos: o símbolo "ramo" distingue projetos relacionados a agricultura, pesca e silvicultura;o ícone de "engrenagem" identifica 
aqueles relativos à industria e ao comércio; os projetos assistenciais e de saúde são representados por uma "cruz"; as intervenções em água, saneamento e inundações são simbolizadas por uma "gota"; a imagem de "livro" representa os projetos relacionados à educação; o ícone "carro" engloba os projetos de transporte; o "templo grego" representaos projetos de administração pública, lei e justiça; o "telefone" refere-se aos projetos de informaçao e comunicação; os projetos financeiros são representados pelo "cifrão"; e o ícone "raio" marcaos projetos que tratam das questões energéticas e de mineração. No Mapa dos Projetos (2016) (Figura 1) não encontramos, no Brasil, as marcações "telefone" e "cifrão".

Desses investimentos, aqueles destinados a "transporte" - que inclui a construção de novas estradas, manutenção e requalificação do sistema rodoviário existente, assim comoos instrumentais e auxiliares à logística e à melhoria do transporte público existente - abarcam quase metade dos recursos investidos ou em implementação, no Brasil. Os projetos em andamento no Brasil relacionados à mobilidade, com vigência de 2010 até 2022, têm dimensões nacionais e estaduais. Dos 4 projetos sob essa rubrica, apenas um é municipal: o projeto "Linha 5 do metrô de São Paulo" (P116170), que representa 46\% dos investimentos em mobilidade em todo o Brasil. A maioria dos projetos se refere à melhoria e à ampliação de sistemas rodoviários intermunicipais e interestaduais.

O projeto Fortalecimento da Gestão Pública e Desenvolvimento Territorial Integrado (P126735), apesar de estar representado no mapa sob o ícone "carro", consiste mais num projeto de gestão, mediado por tecnologias de informação, do que, efetivamente, numa intervenção física na área de mobilidade:

O objetivo do projeto é apoiar o Mutuário para meIhorar a prestação dos serviços através da introdução de tecnologias de informação de gestão com base no desempenho e numa abordagem de desenvolvimento territorial integrado dos serviços públicos essenciais. O projeto proposto terá quatro componentes. As ati- 
vidades propostas irão abranger as seguintes áreas: gestão pública financeira, governança metropolitana e territorial, habitação e regularização fundiária, educação, saúde, meio ambiente e gestão de risco a desastres e desenvolvimento social. ${ }^{17}$ (WORLD BANK, 2016, tradução nossa)

Gráfico 3 - Investimentos do Banco Mundial. Brasil, 2016

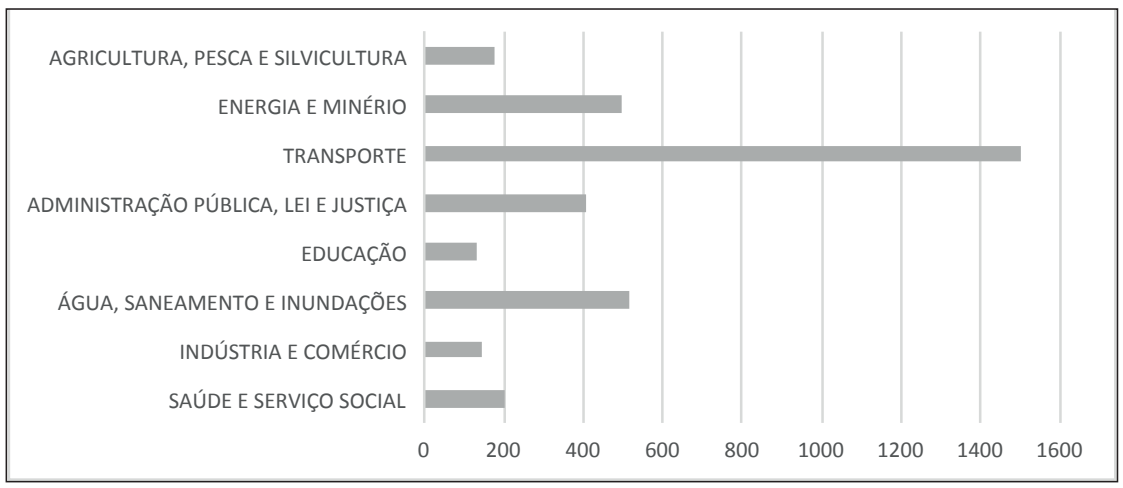

Fonte: elaboração do autor, a partir do mapeamento dos projetos pelo World Bank/Brasil (2016).

Apesar de as agendas incorporarem e darem relevância, gradativamente, ao manejo adequado do meio ambiente e à proteção dos recursos ambientais, os valores investidos nessa rubrica representam menos de $5 \%$ dos valores totais dos projetos em andamento no Brasil, representados pelo "ramo". Os recursos destinados a programas de assistência social totalizam US\$ 200 milhões, a serem investidos de 2010 a 2017, (P101504 - Bolsa Família), atendendo apenas a quatro municipalidades. Apenas um projeto de educação é apoiado pelo Banco Mundial (P126372) e se refere à ampliação do ensino fundamental em Recife, com previsão de US\$130 milhões, de 2012 a 2018.

"Indústria e comércio" sinalizam projetos em infraestrutura urbana e mobilizam \$46 milhões, enquanto os recursos destinados à infraestrutura rural, sob essa mesma rubrica, totalizam $\$ 100$ milhões. $\mathrm{O}$ apoio à agricultura familiar e às pequenas propriedades em proje- 
to desenvolvido no estado do Rio de Janeiro foi alocado sob a rubrica de "ramo": trata-se do projeto "desenvolvimento rural sustentável" (P101508), que atende a 34 localidades, com compromisso originalmente firmado na ordem de US\$34,9 milhões, tendo implementado US\$44,5 milhões e com passivo na ordem de US\$95,15 milhões. No Acre, um projeto também classificadosob a rubrica "ramo" - o "MST economia social sustentável" - atende a 6 localidades, com um valor de US\$120 milhões a serem implementados de 2008 a 2022.

Essa breve descrição dos projetos em andamento no Brasil dá mostras do amplo espectro de atividades apoiadas pelo Banco e mostra a abertura da classificação dos projetos por área temática, dificultando estabelecer, muitas vezes, uma relação mais objetiva entre os objetivos e os compromissos enunciados e as decisões efetivas de apoio aos governos no financiamento dos projetos. Essa imprecisão classificatória das atividades e projetos na destinação dos recursos - considerando-se os objetivos prioritários da agenda anunciada da ONU, a flexibilidade ou amplitude de abordagens dos projetos, que articulam questões sociais e urbanas - coloca indagações sobre o alcance e as prioridades dessas agendas como políticas compartilhadas e sintonizadas com os compromissos anunciados ou prospectados para a agenda urbana e social dos Objetivos do Milênio e do Desenvolvimento Sustentável.

\section{A produção científica sobre a agenda urbana nas ciências sociais: pistas preliminares}

De forma a identificar mudanças no repertório de temáticas assumidas pela produção brasileira nos estudos urbanos, tomou-se o sistema de buscas por temas da SciELO para a pesquisa da produção relacionada a palavras-chave constituintes das agendas urbanas: Agenda 21, Moradia, Assentamento, Questão Urbana, Desenvolvimento Urbano, Governança, Pobreza, Sustentabilidade, Resiliência e Violência Urbana (Gráfico 4). Identificou-se um universo de 374 artigos, produzidos de 1989 até os dias atuais. Foi necessário, no entanto, delimitar alguns termos. Por exemplo, a palavra-chave "violência", sem qualquer 
predicado, apresenta um universo total de quase 8.000 artigos, mas, ao se delimitara busca por "violência urbana", chegou-se apenas a cinco artigos, sabendo-se que muitos indexados sob a palavra-chave "violência" referem-se à sua manifestação urbana. Essa dificuldade confirma a necessidade de aprofundar-se qualitativamente a pesquisa, dada a interseção dos fenômenos manifestos no espaço urbano.

Gráfico 4 - Distribuição de artigos por subtemas urbanos pesquisados. Brasil, 2016

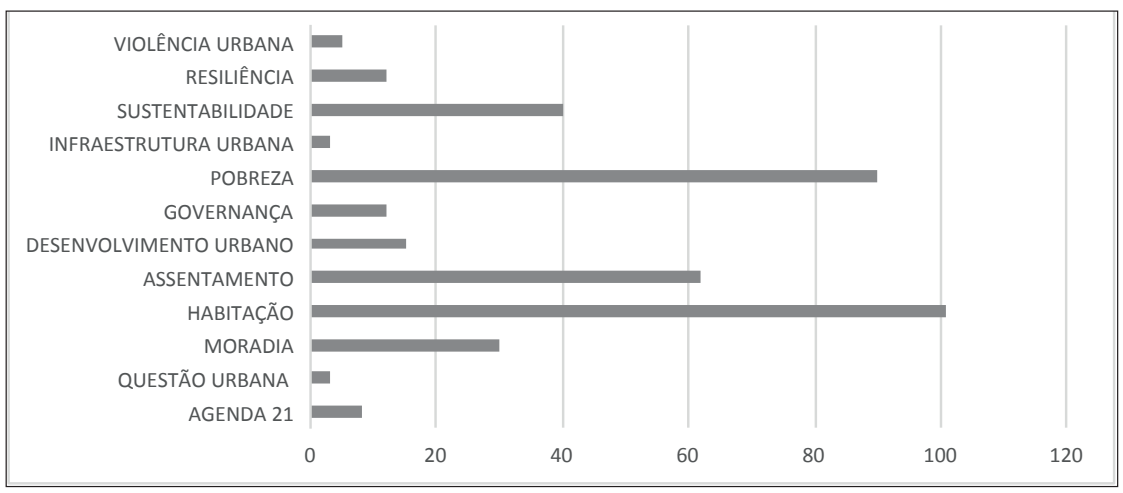

Fonte: elaboração do autor com base no SciELO (2016).

A maior concentração da produção levantada, segundo as palavras-chave pesquisadas, ocorre a partir de 2006, nos diversos termos pesquisados. Destaca-se a magnitude da produção relacionada ao tema "habitação", que abrange $26 \%$ da produção levantada. A palavra "pobreza" figura em segundo lugar, abarcando $23 \%$ dos artigos, sendo o tema de maior tradição de estudos desde 1989 (Gráfico 5).

Os artigos produzidos sobre temáticas relacionadas à agenda urbana - tomando os termos mais recorrentes encontrados nos documentos referenciais -, na base SciELO, integram, em sua maioria, os periódicos da área das Ciências Sociais Aplicadas, segundo critérios de áreas definidos pela SciELO, sendo expressivo o campo das Ciências da Saúde, principalmente em relação à produção relacionada à "pobreza". Contempla também todos os temas pesquisados, com destaque para os estudos sobre "assentamentos". Aqui, uma hipótese permite 
aproximar essa produção na área da saúde talvez em razão da tradição higienista dos primeiros escritos sobre cidade, que nascem associados intimamente às questões de saneamento e saúde.

\section{Gráfico 5 - Evolução da produção nas temáticas urbanas no tempo. Brasil, 1989-2016}

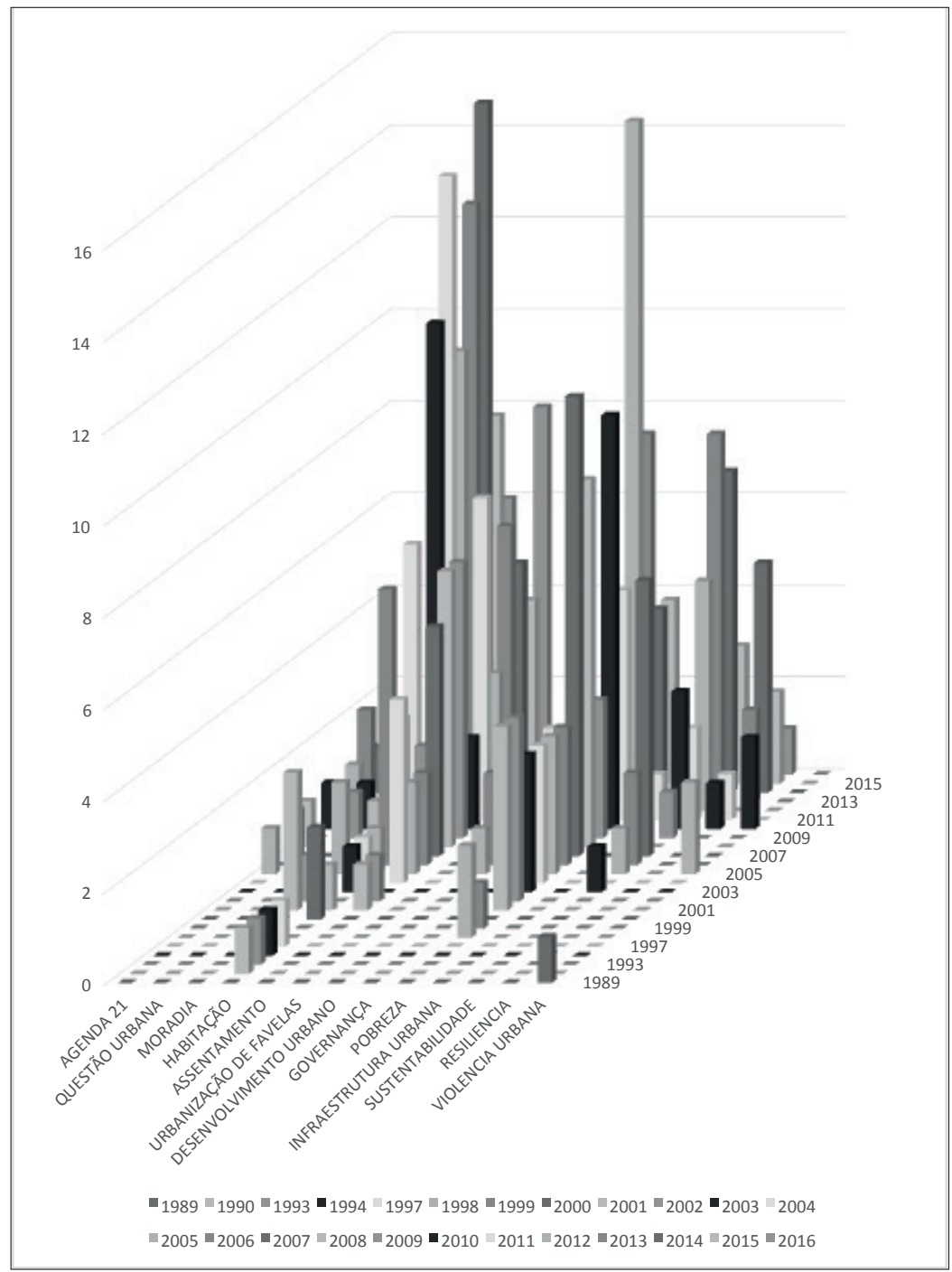

Fonte: elaboração do autor com base no SciELO (2016). 
Gráfico 6 - Produção dos estudos urbanos por área do conhecimento. Brasil, 2016

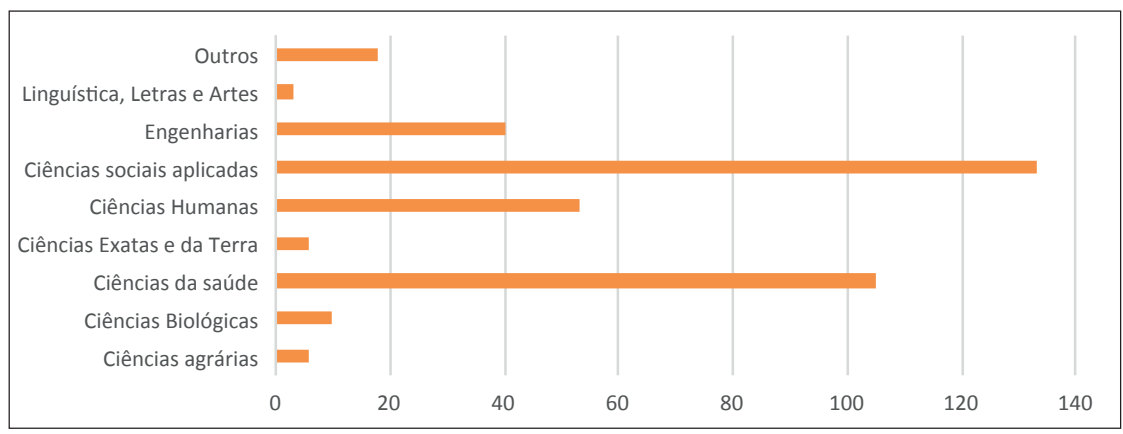

Fonte: elaboração do autor com base no SciELO (2016).

Observada a distribuição das revistas pesquisadas por áreas de conhecimento, a Revista Ambiente Construído, classificada na plataforma SciELO na área das Engenharias, responde por $10 \%$ das publicações, seguida da Ciência da Saúde Coletiva, que integra a área das Ciências da Saúde e responde por quase $6 \%$ dos artigos publicados. A Revista Urbe abarca quase $5 \%$ da produção e o Caderno $C R H$ publica cerca de $4 \%$ da produção sobre o tema das agendas urbanas, integrando essas duas últimas revistas a área das Ciências Sociais. Desse total de revistas, 14 são da área da Sociologia e representam 30,2\% da produção relacionada à agenda urbana pesquisada.

No âmbito das Ciências Sociais Aplicadas, foram identificadas 24 revistas, ${ }^{18}$ sendo14 da subárea da Sociologia e 10 de outras áreas de conhecimento. Das 14 revistas de Sociologia, uma delas - Ciência e Saúde Coletiva - tem interface com a área de Saúde; duas integram a área das Ciências Humanas - Revista Economia e Sociologia Rural e São Paulo Perspectiva - e 13 participam da subárea das Ciências Sociais Aplicadas, respondendo por 30,2\% da produção total das temáticas urbanas pesquisadas. Entre as revistas de Sociologia (na interface com a saúde) a Revista Ciência da Saúde Coletiva representa 18,1\% das publicações, seguida da Revista Urbe com 16\% e o Caderno CRH com 13\%.

Dos 133 artigos levantados pelas palavras-chave na grande área Ciências Sociais Aplicadas, 92 referem-se a publicações em periódicos de 
Sociologia. Outros 22 títulos publicados em revistas de Sociologia estão na área de Ciências da Saúde e cinco títulos em Ciências Humanas, totalizando 119 artigos publicados em revistas de Sociologia que tratam da agenda urbana pesquisada.

É importante destacar que, no universo de artigos publicados em periódicos de Sociologia, aqueles relacionados na pesquisa com as palavras-chave "Agenda 21" e "sustentabilidade" dialogam diretamente com essas agendas: 3 títulos dos 8 levantados na Agenda 21 se fundamentam em documentos e relatórios formulados pela ONU. Dos 40 títulos associados à palavra sustentabilidade, 16 dialogam diretamente com os pressupostos firmados pelas agendas, sendo que apenas 2 mobilizam explicitamente documentação dessas Agências. ${ }^{19}$ Desses artigos, apenas um (OLIVEIRA, 2012) apresenta uma crítica a essas agendas, problematizando as desigualdades sociais e avaliando o caráter instrumental discursivo das "agendas verdes".

Assim, de uma forma geral, os artigos que tratam de temáticas relacionadas à sustentabilidade e ao desenvolvimento sustentável no âmbito dos periódicos de Sociologia, numa primeira avaliação geral, não apresentam uma crítica a esses instrumentais e pressupostos, aderindo normativamente a essas agendas. De uma forma geral, não obstante a natureza crítica em relação às realidades apresentadas, os textos não reconhecem a incorporação das questões sociais como intrínsecas ao ideal sustentável como avanços e desafios futuros relevantes para as transformações sociais e a justiça social. A participação social mais ampla, como princípio fundamental para a efetivação desses pressupostos verdes, também constitui elemento convergente dessas agendas. Consonante com as diretrizes dos Objetivos do Desenvolvimento Sustentável, as questões de sustentabilidade e aquelas sobre o manejo e a gestão ambiental constituem eixos investigativos de grande relevância na produção da Sociologia contemporânea, articulada diretamente à problemática anunciada pelas agendas internacionais.

Num outro sentido, as pesquisas com base nos termos habitação, moradia, pobreza, governança e violência urbana, buscadas nas revistas de Sociologia, apresentam, pela natureza dos objetos analisados, 
um diálogo com essas agendas urbanas de natureza diversa daquele encontrado nas pesquisas com os temas Agenda 21 e sustentabilidade. Nesse caso, não encontramos um número expressivo do manuseio de documentos das agências internacionais. De uma forma geral, pela natureza dos trabalhos ou pelos temas estruturais tradicionalmente tratados pelo campo da Sociologia, as abordagens encontradas nessas pesquisas, em sua maioria, constituem análises mais autônomas em relação aos pressupostos apresentados nas agendas urbanas pelas organizações internacionais. Nesse universo, as questões relativas ao direito à cidade atravessam os diversos temas associados à cidade, o que se evidencia em análises sobre os modelos gestores urbanos, na atuação estatal territorializada ou, ainda nas problemáticas relativas à participação e à cidadania nas cidades.

Considerando, de forma cautelosa, os dados levantados, a produção de artigos sobre estudos urbanos confirma, em parte, a convergência entre a agenda da ONU e a produção acadêmica de estudos urbanos. A noção assentamento expressa, em parte, essa influência, por ser um termo recorrente nos documentos do Habitat que reúnem um número significativo de artigos publicados, evidenciando uma interseção entre a produção acadêmica nacional e a formulação das problemáticas das agências internacionais - com especial destaque para as questões relacionadas à regularização fundiária urbana, como objeto básico para a cidadania. O caráter interdisciplinar das questões urbanas se expressa na reconstrução de problemáticas em diálogos com diversos campos disciplinares, como se percebe na formulação das agendas e nos documentos referenciais apresentados.

No âmbito das Ciências Sociais Aplicadas, evidencia-se um lapso temporal entre o momento da formulação do Programa Habitat e a produção acadêmica sobre o tema no Brasil. Por exemplo, as normativas do Habitat em relação aos "assentamentos urbanos" aparecem como pauta no final dos anos 1990, enquanto a produção acadêmica no Brasil que carrega essa terminologia vai aparecer nos anos 2000, ganhando maior destaque a partir de 2010. 
Por outro lado, a amplitude das questões e temas que desdobram a agenda urbana dificulta determinar uma correlação direta entre as orientações dos programas da ONU-Habitat e do PNUD na produção sociológica brasileira. Em realidade, essa intercorrência se faz num ir e vir entre a emergência de problemas de pesquisa, os avanços no processo do conhecimento e suas formulações, e a interação na discussão desses problemas em fóruns e encontros mundiais da Habitat e nas discussões nos países que incorporam, recompõem e processam essa agenda, transformando-a numa agenda de compromissos globais e também em novas agendas de pesquisa.

\section{Considerações finais}

Este ano (2016) ocorrerá o Habitat III. No Brasil, inúmeros even$\operatorname{tos}^{20}$ mobilizam a comunidade acadêmica na construção de agendas e levantamentos de temáticas específicas à realidade brasileira, ratificando a mobilização dos diversos agentes na renovação da agenda urbana, que, somada à atuação de expertises associados a ONU-Habitat, no Brasil, contribui significativamente para a formulação de prognósticos e novos desafios para as cidades brasileiras. Assim, esses espaços de mobilização e debate constituem instâncias de formulação de problemáticas urbanas pacificadas e não conflitivas no âmbito local (a exemplo das questões de prevenção contra riscos e desastres ou de afirmações morais contra a pobreza). Em alguns casos, são esferas relevantes de crítica e, portanto, de análise de assimetrias dos processos de desigualdades na distribuição dos bens públicos ou na repactuação entre atores sociais locais em relação ao direito à cidade.

No âmbito internacional, encontra-se aberta e disponível uma agenda, "Rascunho Zero", ${ }^{21}$ que conduzirá os trabalhos e produtos da conferência internacional e que objetiva aprovar uma nova agenda urbana, a ser finalizada na Habitat III, que ocorrerá no Equador em outubro de 2016. Esse documento, base da pactuação mundial de uma nova agenda urbana e de atualização da agenda urbana vigente, mobiliza uma articulação no âmbito nacional que tem como resultado a 
Carta da sociedade civil brasileira sobre a Nova Agenda Urbana a ser adotada no Habitat III.

Essa carta reconhece avanços nas questões urbanas e nos temas propostos pelo documento Rascunho Zero: a integração entre o entendimento das políticas de cidades e as habitacionais e suas diversas escalas é reconhecida como avanço. No entanto, segundo essa carta, o Rascunho Zero é lacunar no que diz respeito a uma análise mais aprofundada sobre questões postas pelo Habitat II. A aparente neutralidade da abordagem sobre o desenvolvimento urbano é apontada como contraditória em relação a uma realidade cotidianamente vivenciada pelas populações, marcada pela exclusão, regressão e violação de direitos:

Com isso, não reconhece nem mostra empatia pelos diversos conflitos que permeiam este processo, como os conflitos fundiários, socioambientais e de disputa política pelo espaço público, presentes em diferentes partes do mundo. (CARTA DA SOCIEDADE..., 2016)

Nesse sentido, formula-se uma crítica à noção de pobreza urbana medida exclusivamente pelo quesito da renda, sem avançar nas questões referentes a desigualdades socioterritoriais e nas problemáticas específicas de grupos marginalizados - maiores vítimas da violência urbana (mulheres, idosos, povos tradicionais, LGBTs etc.). A Carta aponta, ainda, objetivos contraditórios do documento Rascunho Zero, como o objetivo de construir economias urbanas inclusivas versus a competitividade apresentada como meta.

Por fim, os signatários ${ }^{22}$ dessa carta apontam para a necessidade de se incorporar à agenda urbana em construção maior delineamento e clareza quanto à atuação dos atores privados, a regulação de grandes empresas e a garantia de participação, como fundamentos do "Direito à Cidade":

Acreditamos, assim, que a NAU deve reconhecer o Direito à Cidade como uma abordagem de direitos humanos para as cidades e como uma plataforma de ação para governos, sociedade civil, e setor privado, 
com vistas às cidades justas, inclusivas e sustentáveis. Nesse sentido ainda, é importante que a NAU defina com mais clareza o papel do setor privado no processo de desenvolvimento urbano para além das parcerias público-privadas. É importante estabelecer mecanismos de participação, controle social, gestão e transparência para sua atuação e nas relações estabelecidas com o setor público e a sociedade. São necessárias, portanto, políticas de regulação das grandes empresas atuantes no setor e também do mercado imobiliário. Também devem ser previstas políticas que consigam reverter o atual padrão excludente de desenvolvimento urbano, desconcentrar a propriedade privada e redistribuir melhor as riquezas e benefícios decorrentes do processo de produção das cidades, inclusive por meio da criação de impostos progressivos e da inversão de prioridades nos investimentos. ${ }^{23}$ (CARTA DA SOCIEDADE..., 2016)

Assim, a Carta da sociedade civil brasileira sobre a Nova Agenda Urbana a ser adotada no Habitat III retorna à tese clássica do "Direito à Cidade", resgatando a sua natureza de polis e expondo o caráter político da produção das cidades-mercado. Explicita, ainda, formas de articulação crítica entre a produção acadêmica, as agendas urbanas das cidades e as orientações e diretrizes da ONU-Habitat na pactuação global de diretrizes do desenvolvimento urbano sustentável.

A identificação dos projetos em andamento no Brasil, financiados pelo Banco Mundial, evidencia outro campo de influência dessas agências multilaterais na implementação das ações de governo das cidades. A natureza desses projetos e as formas concretas de intervenção revelam um campo fronteiriço no que diz respeito aos objetivos prospectados pela Agenda Habitat e os ODS. As ações, traduzidas em termos de financiamento, revelam orientações e prioridades definidas por recursos. Comparadas com as prioridades e compromissos assumidos pelo Banco na redução de $50 \%$ da pobreza mundial e sua ação como agência econômica e de crédito no suporte a empreendimentos produtivos e de infraestrutura, essas ações mostram uma distância en- 
tre intenções discursivas enunciadas e o fomento financeiro a projetos em andamento, ainda que se reconheça o papel que possam ter na redução da pobreza. Os enunciados morais de enfrentamento da pobreza em favor de maior equidade nas cidades são compromissos mais amplos de justiça social, mas garantidos pela dinamização de empreendimentos de infraestrutura e moradia.

A complexidade da estrutura organizacional das agências multilaterais evidenciou uma orquestração das ações dos diversos programas e órgãos associados e a articulação, correlação e fortalecimento mútuo de suas agendas temáticas, no que diz respeito aos princípios e orientações de áreas e questões urbanas. Elas aparecem tanto nas agendas denominadas especificamente de urbanas, como na gestão de riscos e catástrofes relacionadas ao meio ambiente, como também perpassam aquelas direcionadas às questões sociais e políticas.

$\mathrm{Na}$ forma definida pela ONU-Habitat, as agendas urbanas tratam de questões como a pobreza, a diversidade cultural e de gênero, introduzindo problemáticas tradicionalmente tratadas por outros campos disciplinares, como questões sociais, econômicas e (ou) culturais. Essa interdisciplinaridade das problemáticas impõe um esforço adicional na produção de metodologias orientadas para aprofundar e decifrar problemas de campos disciplinares singulares. Do mesmo modo, só da perspectiva interdisciplinar se pode avaliar o poder de influência dessas agências sobre a produção sociológica contemporânea. O fato é que a agenda urbana pactuada na ONU-Habitat contempla a definição de campos de prioridades que se metamorfoseiam no tempo, acompanhando os processos mais amplos de transformação social e política, as formas de pactuação entre os agentes corporativos e os Estados, assumindo especificidades na relação entre os agentes sociais no âmbito local.

Essa ressignificação das problemáticas urbanas incorpora um olhar entrecruzado no espaço territorializado das cidades e metrópoles, o que envolve consequências políticas no encaminhamento de soluções, assim como inaugura competências externas a seu campo disciplinar original, para pensar o urbano pelo social, pelo econômico, pelo político, pelo cultural e pelo ambiental. Essa exigência epistemo- 
lógica, somada à complexidade dos arranjos institucionais, constitui um desafio extra a essa pesquisa no campo do conhecimento, impondo pensar como as questões do desenvolvimento urbano respondem a agendas estrangeiras ao país, ou afirmam esse campo do conhecimento assumindo um compromisso com os princípios de desenvolvimento sustentável compatível com o direito à cidade, para a cidadania.

\section{Referências}

IBAM. Instituto Brasileiro de Administração Municipal. Agenda Habitat para Municípios. Coordenado por Marlene Fernandes. Rio de Janeiro: IBAM, 2003. Disponível em: <http://www.participa.br/articles/public/0007/9445/Agenda_ Habitat_para_Munic_pios_Brasil.pdf>. Acesso em: 19 jun. 2016.

ANTONUCCI, D. et al. UN-Habitat: 3 décadas de atuação. Arquitextos, v. 9, abr. 2009. Disponível em: <http://www.vitruvius.com.br/revistas/read/ arquitextos/09.107/56>. Acesso em: 18 jun. 2016.

ARANTES, O. Urbanismo em fim de linha. São Paulo: EdUSP, 2001.

ASCHER, F. Os novos princípios do urbanismo. São Paulo: Romano Guerra, 2010. BIDOU-ZACHARIASSEN, C. Introdução. In: BIDOU-ZACHARIASSEN, C. (Org.). De volta à cidade: dos processos de gentrificação às políticas de "revitalização" dos centros urbanos. São Paulo: Annablume, 2006.

BORJA, J.; CASTELLS, M. Local y global: La gestión de las ciudades en la era de la información. Espanha: Taurus, 1997.

BRASIL. Presidência da República. Lei n. 10.257. Estatuto da Cidade, de 10 de julho de 2001. Disponível em: <https://www.planalto.gov.br/ccivil_03/leis/ leis_2001/110257.htm> Acesso em: 22 out. 2016.

CARTA ABERTA ao governo brasileiro sobre o fechamento do Centro de Excelência para a Redução do Risco de Desastres (UNISDR-CERRD). 2015. Disponível em: <http://www.abergo.org.br/arquivos/noticias/Carta\%20 Aberta\%20ao\%20Governo\%20Brasileiro\%20Rede\%20Pesquisas\%20RRD.pdf >. Acesso em: 1 jul. 2016.

CARTA DA SOCIEDADE civil brasileira sobre a nova agenda urbana a ser adotada no Habitat III. 2016. Disponível em: <http://www.archdaily.com. $\mathrm{br} / \mathrm{br} / 791691 / \mathrm{carta}$-da-sociedade-civil-brasileira-sobre-a-nova-agendaurbana-a-ser-adotada-no-habitat-iii . Acesso em: 27 jul. 2016.

CHOAY, F. O urbanismo. São Paulo: Perspectiva, 1979. 
DECLARAÇÃO DE ISTAMBUL SOBRE ASSENTAMENTOS HUMANOS. 1996. In: IBAM. Instituto Brasileiro de Administração Municipal. Agenda Habitat para Municípios. Coordenado por Marlene Fernandes. Rio de Janeiro: IBAM, 2003. Disponível em: <http://www.participa.br/articles/public/0007/9445/Agenda Habitat_para_Munic_pios_Brasil.pdf>. Acesso em: 19 jun. 2016.

DECLARAÇÃO SOBRE CIDADE E OUTROS ASSENTAMENTOS HUMANOS NO NOVO MILÊNIO. 2001. In: IBAM. Instituto Brasileiro de Administração Municipal. Agenda Habitat para Municípios. Coordenado por Marlene Fernandes. Rio de Janeiro: IBAM, 2003. Disponivel em: <http://www. participa.br/articles/public/0007/9445/Agenda_Habitat_para_Munic_pios Brasil.pdf>. Acesso em: 19 jun. 2016.

DECLARAÇÃO SOBRE CIDADE E OUTROS ASSENTAMENTOS HUMANOS NO NOVO MILÊNIO. Zero Draft the New Urban Agenda. 2016. Disponível em: <https://www.habitat3.org/ bitcache/462d74cfb2e04878ff43c8fcca48037daf73d84f?vid =582559\&disposition=inline\&op=view>. Acesso em: 1 jul. 2016 .

FERNANDES, A. Decifra-me ou te devoro: urbanismo corporativo, cidadefragmento e dilemas da prática do Urbanismo no Brasil. In: GONZALES, S. F. N.; FRANCISCONI, J. G.; PAVIANI, A. Planejamento e urbanismo na atualidade brasileira: objeto, teoria, prática. São Paulo: Rio de Janeiro: Livre Expressão, 2013.

FRANCO, Â. Em tempos globais, um "novo" local: a Ford na Bahia. Caderno CRH, Salvador, v. 22, n. 56, p. 359-380, maio/ago. 2009.

HARVEY, D. Condição pós-moderna. São Paulo: Edições Loyola, 1996.

HARVEY, D. A produção capitalista do espaço. São Paulo: Annablume, 2006.

HARVEY, D. Wall Street e o direito à cidade. Le Monde Diplomatique - Brasil, ano 2, n. 20, mar. 2009.

HARVEY, D. Cidades rebeldes: do direito à cidade à revolução urbana. São Paulo: Martins Fontes, 2014.

IVO, Anete B. L. L'expérience de gouvernance urbaine à Salvador de Bahia (1993-1996).Gestion urbaine, pouvoir et légitimité. Les Annales de laRecherche Urbaine, Paris, n. 80-81, p. 55-63, 1998.

IVO, Anete B. L. Metamorfoses da questão democrática: governabilidade e pobreza. Buenos Aires: CLACSO: ASDI, 2001.

IVO, Anete B. L. A 'urban governance' e as políticas sociais: entre consentimento e emancipação. In: ZICCARDI, A. (Comp.). Participación Ciudadana y Políticas Sociales en el ámbito Local. México: IISUNAM/Consejo Mexicano de Ciencias Sociales- COMECSO/INDESOL, 2004. p. 77-104. 
IVO, Any. B. L. Para além dos jogos de futebol: o processo de reestruturação das cidades para a Copa de 2014 e a "marca Brasil". Salvador: Edufba, 2015.

LEFEBVRE, H. O direito à cidade. Tradução Rubem Eduardo Frias. 5. ed. São Paulo: Centauro, 2001.

ONU Brasil. OBJETIVO 11-ODS. Objetivos do Desenvolvimento Sustentável. Tornar as cidades e os assentamentos humanos inclusivos, seguros, resilientes e sustentáveis. Disponível em: <https://nacoesunidas.org/pos2015/ods11/>. Acesso em: 19 jun. 2016.

OLIVEIRA, J. A. Puppim de. Rio+20: What We Can Learn from the Process and What is Missing. Cad. EBAPE.BR, Rio de Janeiro, v. 10, n. 3, p. 492-507, set. 2012.

ONU. Organização das Nações Unidas. Declaração do Milênio. Disponível em: <https://www.unric.org/html/portuguese/uninfo/DecdoMil.pdf>. Acesso em: 19 jun. 2016.

ONU. Organização das Nações Unidas. Declaração Universal dos Direitos Humanos. 1948. Disponível em: <http://unesdoc.unesco.org/ images/0013/001394/139423por.pdf>. Acesso em: 19 jun. 2016.

ONU-HABITAT. Programa das Nações Unidas para os Assentamentos Humanos. Disponível em: <https://nacoesunidas.org/agencia/onu-habitat/>. Acesso em: 19 jun. 2016.

ONU-HABITAT. Programa das Nações Unidas para os Assentamentos Humanos. The Vancouver Declaration nn Human Settlements, 1976a.

Disponível em: <http://habitat.igc.org/vancouver/van-decl.htm>. Acesso em: 19 jun. 2016.

ONU-HABITAT. Programa das Nações Unidas para os Assentamentos Humanos. The Vancouver Action Plan, 1976b. Disponível em: <http://habitat. igc.org/vancouver/vp-intr.htm>. Acesso em: 19 jun. 2016.

ONU-HABITAT. Programa das Nações Unidas para os Assentamentos Humanos. Sendai Framework for Disaster Risk Reduction 2015 -

2030. Disponivel em: <http://www.preventionweb.net/files/43291_ sendaiframeworkfordrren.pdf>. Acesso em: 19 jun. 2016.

SÁNCHEZ, F. A reinvenção das cidades para o mercado mundial. Porto Alegre: Argos, 2010.

SANTOS, M. A natureza do espaço. São Paulo: EdUSP, 2009.

SASSEN, S. Global City. Nova Jersey: Princeton University, 2001.

UNISDR. The United Nations Office for Disaster Risk Reduction. Terminology. [2016]. Disponível em: <http://www.unisdr.org/we/inform/terminology>. Acesso em: 19 jun. 2016. 
UNISDR. The United Nations Office for Disaster Risk Reduction. Como construir cidades mais resilientes: um guia para gestores públicos locais. Uma contribuição à campanha 2010-2015 - Construindo cidades resilientes, minha cidade está se preparando! Genebra, 2012. Disponível em: <http:// www.unisdr.org/files/26462_guiagestorespublicosweb.pdf>. Acesso em: 19 jun. 2016.

VAINER, C. Pátria, empresa e mercadoria. In: ARANTES, O.; VAINER, C.; MARICATO, E. A cidade do pensamento único: desmanchando consensos. Petrópolis, RJ: Vozes, 2007.

VELTZ, P. Mundialização, ciudades e territórios. Barcelona: Ariel, 1999.

WORLD BANK. Informe Anual 2013. Disponível em: <https://openknowledge. worldbank.org/bitstream/handle/10986/16091/9780821399446SP. pdf? sequence=7\&isAllowed=y>. Acesso em: 20 jun. 2016.

WORLD BANK. Mapa de projetos: Brazil. Disponível em: <http://maps.worldbank. org/p2e/mcmap/map.html?org=ibrd\&level=country\&code=BR\&title=Brazill . Acesso em: 19 jun. 2016.

\section{Notas explicativas}

1 Sassen (2001), Harvey (2006), Veltz (1999), Santos (2009), entre outros.

2 Entendemos como "urbanismo tradicional" a atividade de planejar a cidade mediante um plano conjunto, com vistas a corrigir os desequilíbrios da qualidade de vida, dos custos e funcionamento do urbano, tendo o Estado um papel central pela estrutura dos serviços e equipamentos básicos, assegurando a todos os seus habitantes, moradia e qualidade de vida. Ver: Choay (1979), Ascher (2010), Arantes (2001), entre outros.

3 A cidade polarizada em classes, grupos sociais e ilhas culturais, tendo como resultado a segregação e a fragmentação do espaço urbano. Cf. Sassen (2001), Borja e Castells (1998), Santos (2009), entre outros.

4 Sobre urbanismo corporativo e modelos afins, ver: Fernandes (2013), Franco (2009), Vainer (2009), Sanchez (2010), entre outros.

5 A reinvenção do desenvolvimento: agencias multilaterais e produção sociológica contemporânea. Projeto Universal do CNPq apoiado pelo Edital n. 14 de 2012, coordenado por Anete B. L. Ivo e executado no âmbito do Centro de Estudos e Pesquisas em Humanidades (CRH) e no Programa de Pós-Graduação em Ciências Sociais da Faculdade de Filosofia da Universidade Federal da Bahia (UFBA). O projeto iniciou-se em 2012, mas a minha inserção na equipe ocorre em 2016.

6 A Agenda 21 consiste em documento elaborado na Conferência das Nações Unidas sobre o Meio Ambiente e o Desenvolvimento (CNUMAD), conhecida como Rio 92, que teve como objetivo a formulação de diretrizes para o desenvolvimento sustentável para o século XXI. 
7 A Declaração Universal dos Direitos Humanos determina que todo indivíduo tem direito à livre locomoção e residência no seu país, à participação política, aos serviços públicos e a um padrão de vida que garanta saúde, educação e bem-estar, dando condições para habitar, vestir, gozar de lazer, cuidados médicos etc.

8 O Escritório das Nações Unidas para Redução de Riscos e Desastres (UNISDR) define resiliência como a capacidade do sistema, quando exposto a riscos, de resistir, adaptar-se e recuperar-se de forma eficiente, restaurando sua estruturação básica e sua função essencial. Essa definição figura entre outras definições apresentadas num catálogo de terminologias relacionadas às questões de risco, catástrofes e desastre. Ver: Terminology (UNISDR, [2016]).

9 Ver: ONU-HABITAT - Sendai Framework for Disaster Risk Reduction 2015 - 2030, 2016.

10 "Human settlement policies can be powerful tools for the more equitable distribution of income and opportunities". (ONU-Habitat, 1976b)

11 "Land is one of the fundamental elements in human settlements. Every State has the right to take the necessary steps to maintain under public control the use, possession, disposal and reservation of land. Every State has the right to plan and regulate use of land, which is one of its most important resources, in such a way that growth of population centers both urban and rural are based on a way that the growth of population centers both urban and rural are based on a comprehensive and use plan. Such measures must assure the attainment of basic goals of social and economic reform for every country, in conformity with its national and land tenure system and legislation." (ONU-Habitat, 1976a)

12 "The highest priority should be placed on the habilitation of expelled and homeless people who have been displaced by natural or man-made catastrophes, and especially by the act of foreign aggression. In the latter case, all countries have the duty to fully co-operate in order to guarantee that the parties involved allow there turn of displaced persons to their homes and to give them the right to possess and enjoy their properties and belongings without interference." (ONU-Habitat, 1976a)

13 "In fact, the very construction of the physical components of human settlements - be they rural or urban, in the form of dwelling so roads, with traditional or modern technologies - in sufficient volume to meet the needs of society, could become a leading sector of the economy and a major generator of meaning full employment, instead of being treated as a residual of so-called "productive" activities". (ONU-Habitat, 1976b)

14 "A co-operative effort to the people and their Governments is a prerequisite for effective action on human settlements. The magnitude and intractability of the problems are too great for Governments to act alone. Citizen participation should be an integral part of the decision-making processes on the full range of human settlement issues. Citizens must be provided opportunities for direct involvement in the decisions that profoundly affect their lives. Such participation can heighten citizen awareness of the complexity and interrelatedness of the problems and the urgent need for concerted action. Involvement of citizens can also be an important means of making creative use of their ingenuity and skills, thus making effective use of often untapped sources." (ONU-Habitat, 1976b)

15 Segundo a Agenda Habitat (1996), os Assentamentos Humanos Sustentáveis garantem o desenvolvimento econômico, a oportunidade de emprego e o progresso social, em harmonia com o meio ambiente, relacionado ao desenvolvimento sustentável (com especial atenção à boa gestão dos recursos escassos: água e terra).

16 "El Grupo del Banco Mundial ha entrado en una nueva era al adoptar objetivos mensurables para poner fin a la pobreza extrema en todo el mundo hacia 2030 y promover la prosperidad 
compartida, metas que procurará alcanzar de un modo sostenible en lo ambiental, social y económico. Para lograr estos objetivos, será necesario reconocer que el crecimiento económico por sí solo no conducirá al bienestar sostenido e inclusivo. El aumento en los niveles de malestar social en todo el mundo fue provocado, en parte, por una mayor desigualdad económica y por la falta de oportunidades de inclusión. Lograr estos objetivos supondrá una mayor cooperación entre los asociados en la tarea del desarrollo, entre los que figuran las organizaciones multilaterales y los Estados que las componen. Esta cooperación es esencial en un momento de continua incertidumbre económica en todo el mundo." (WORLD BANK, 2013, p. 7)

17 "The objective of the Project is to support the Borrower to improve service delivery through introducing performance-based management information technologies and an Integrated Territorial Development Approach in key public services. The proposed project will have four components. The proposed activities will encompass the following areas: public financial management, metropolitan and territorial governance, housing and land regularization, education, health, environment and disaster risk management, and social development." (WORLD BANK, 2016)

18 Anais do Museu Paulista; Economia e Sociedade; Estudos Econômicos; Lua Nova; Novos Estudos CEBRAP; RAM, Revista de Administração da Mackenzie; REA, Revista Eletrônica de Administração; Revista de Administração Contemporânea; Revista de Administração Pública; Sociedade e Natureza; Texto Contexto; Ambiente e Sociedade; Caderno CRH; Caderno EBAPE. Br.; Cadernos da Metrópole; Interações; Organização e Sociedade; Revista Brasileira de Ciências Sociais; Sociedade e Estado; Sociologias; Tempo social; Urbe, Revista Brasileira de Gestão Urbana.

19 O documento Report of the World Commission on Environment and Development: Our Common Future, também conhecido como Relatório de Brundtland, 1987, pela primeira vez trata do desenvolvimento sustentável, ou seja, inaugura a discussão acerca o meio ambiente e o desenvolvimento como um único problema.

20 Seminário Internacional hacia Hábitat III; "HABITAT III, desafios da Nova Agenda Urbana e a população em Situação de Rua" (UFPR); Oficina "Relatório preliminar brasileiro para o Habitat III", ocorrida no seminário URBA [15] - Direito à Cidade/UFBA; Habitat 2015 - Habitação e desenvolvimento sustentável (Belo Horizonte), entre outros.

21 Ver: DECLARAÇÃO SOBRE CIDADE E OUTROS ASSENTAMENTOS HUMANOS NO NOVO MILÊNIO (2016).

22 Assinam a "Carta da sociedade civil brasileira sobre a Nova Agenda Urbana a ser adotada no Habitat III": ActionAid Brasil; Instituto A Cidade Precisa de Você; Associação Nacional de Transportes Públicos; Central de Movimentos Populares; Centro de Direitos Econômicos e Sociais; Centro Dom Hélder Câmara de Estudos e Ação Social(CENDHEC); Centro Gaspar Garcia; Confederação Nacional das Associações de Moradores; Engajamundo; Escola de Governo São Paulo; Federação de Órgãos para Assistência Social e Educacional (FASE); Federação Interestadual de Sindicatos de Engenheiros; Federação Nacional dos Arquitetos e Urbanistas - FNA; Fórum Nacional de Reforma Urbana; Frente de Luta por Moradia; Fundo Socioambiental Casa; Global Platform for the Right to the City; Habitat para Humanidade Brasil; Instituto Brasileiro de Direito Urbanístico; Instituto Pólis; Grupo de Pesquisa Lugar Comum/FAUFBA; Movimento Nacional de Luta por Moradia; Grupo de Pesquisa Meio Ambiente Urbano da PUC/SP; Rede Interação; Street Net; Terra de Direitos; Teto - Brasil; União de Moradia da Zona Sul; União dos Movimentos de Moradia de São Paulo; União Nacional por Moradia Popular.

23 NAU (Nova Agenda Urbana). 